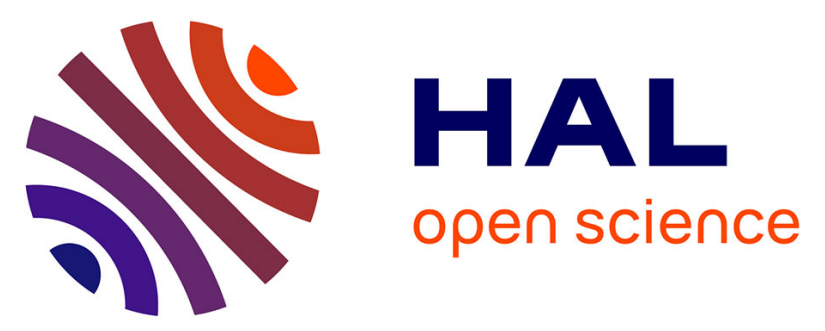

\title{
Twisted Intramolecular Charge Transfer in Protonated Amino Pyridine
}

Michel Broquier, Satchin Soorkia, Claude Dedonder-Lardeux, Christophe Jouvet, Patrice Theulé, Gilles Grégoire

\section{To cite this version:}

Michel Broquier, Satchin Soorkia, Claude Dedonder-Lardeux, Christophe Jouvet, Patrice Theulé, et al.. Twisted Intramolecular Charge Transfer in Protonated Amino Pyridine. Journal of Physical Chemistry A, 2016, 120 (3797), 10.1021/acs.jpca.6b03510 . hal-01346468

\section{HAL Id: hal-01346468 \\ https://hal.science/hal-01346468}

Submitted on 19 Jul 2016

HAL is a multi-disciplinary open access archive for the deposit and dissemination of scientific research documents, whether they are published or not. The documents may come from teaching and research institutions in France or abroad, or from public or private research centers.
L'archive ouverte pluridisciplinaire HAL, est destinée au dépôt et à la diffusion de documents scientifiques de niveau recherche, publiés ou non, émanant des établissements d'enseignement et de recherche français ou étrangers, des laboratoires publics ou privés.

\section{다)(1) $(5$}

Distributed under a Creative Commons Attribution - NonCommercial| 4.0 International 
Reprinted with permission from The Journal of Physical Chemistry A.

J. Phys. Chem. A, 2016, 120 (21), pp 3797-3809 DOI: 10.1021/acs.jpca.6b03510

\title{
Twisted Intramolecular Charge Transfer in Protonated Amino Pyridine
}

\author{
Michel Broquier, ${ }^{a, b}$ Satchin Soorkia, ${ }^{a}$ Claude Dedonder-Lardeux,${ }^{c}$ Christophe Jouvet ${ }^{c}$, Patrice \\ Theuléc $^{c}$ and Gilles Grégoire ${ }^{a, b}$ \\ ${ }^{a}$ Institut des Sciences Moléculaires d'Orsay (ISMO), CNRS, Univ. Paris Sud, Université Paris- \\ Saclay, F-91405 Orsay (France)

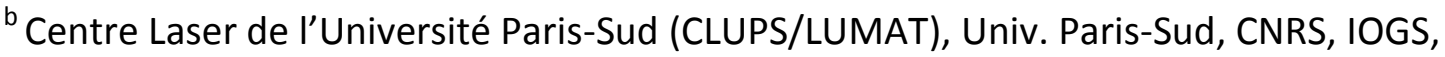 \\ Université Paris-Saclay, F-91405 Orsay (France) \\ 'CNRS, Aix-Marseille Université, PIIM UMR 7365, Avenue Escadrille Normandie-Niémen, \\ 13397 Marseille Cedex 20, France
}

Corresponding author: gilles.gregoire@u-psud.fr

\begin{abstract}
The excited state properties of protonated ortho (2-), meta (3-) and para (4-) aminopyridine molecules have been investigated through UV photo fragmentation spectroscopy and excited state couple cluster CC2 calculations. Cryogenic ion spectroscopy allows recording well-resolved vibronic spectroscopy that can be nicely reproduced through Franck Condon simulations of the $\pi \pi^{*}$ local minimum of the excited state potential energy surface. The excited state lifetimes have also been measured through a pump-probe excitation scheme and compared to the estimated radiative lifetimes. Although protonated aminopyridines are rather simple aromatic molecules, their deactivation mechanisms are indeed quite complex with unexpected results. In protonated 3- and 4aminopyridine, the fragmentation yield is negligible around the band origin, which implies the absence of internal conversion to the ground state. Besides, a twisted intramolecular charge transfer reaction is evidenced in protonated 4-aminopyridine around the band origin, while excited state proton transfer from the pyridinic nitrogen to the adjacent carbon atom opens with roughly $500 \mathrm{~cm}^{-1}$ of excess energy.
\end{abstract}




\section{Introduction}

The photo dynamical behavior of model hetero aromatic rings is of great interest since it provides a deep understanding of the properties of benchmark systems suitable to investigate more complex molecular species. Among these heterocycles, DNA and RNA bases are ubiquitous with intrinsic stability against photo induced damages. ${ }^{1,2}$ While their short excited state lifetimes reveal a common rapid decay to the electronic ground state, several distinct deactivation paths have been theoretically emphasized. Conical intersection $(\mathrm{Cl})$ connecting directly the locally excited $\pi \pi^{*}$ state to the electronic ground state can be reached through out-of-plane vibrational modes, involving ring deformation and bending of the amino group as predicted for cytosine ${ }^{3,4}$ and guanine. ${ }^{5}$ The potential energy surfaces (PES) in the Franck-Condon region are generally quite complex with several low-lying excited states of different electronic characters such as $\pi \pi^{*}$ and $n \pi^{*}$ with the lone pair on the oxygen and/or nitrogen atoms. Surface crossings between the bright $\pi \pi^{*}$ state and dark $n \pi^{*}$ states thus further complicate the possible relaxation mechanisms. ${ }^{6}$ A way to simplify the photo dynamical process would be to suppress the $n \pi^{*}$ state, for instance by protonation at the nitrogen site.

Indeed, while most of the experimental and theoretical works of the last two decades have been devoted to neutral species, the study of protonated nucleobases and related species has now emerged with the advent of cryogenic ion spectroscopy. For instance, we have recently investigated the photochemical properties of protonated azine, diazines and DNA/RNA bases following electronic excitation. ${ }^{7,8}$ Sub picosecond excited state lifetimes have been estimated from line broadening of the vibronic bands when one nitrogen atom of the ring is not protonated, revealing the influence of a $\mathrm{n}_{\mathrm{N}} \pi^{*}$ state upon the deactivation of the $\pi \pi^{*}$ state. Besides, even in molecules that do not have a lone pair orbital on nitrogen, a dramatic lifetime shortening of 4 order of magnitude has been observed with a single functional group substitution $\left(\mathrm{OH}\right.$ vs $\left.\mathrm{NH}_{2}\right)$ in protonated keto-enol uracil and keto-amino cytosine, respectively. We thus have undertaken a systematic study of the influence of the position of the amino group in protonated aminopyridine molecules.

2-, 3- and 4-aminopyridine (AP) are simple molecules that could act as biomimetic of pyrimidine bases. In their neutral forms, they indeed have short excited state lifetimes with low fluorescence yield, revealing efficient non-radiative process. ${ }^{9}$ Their radiative rate are greatly increased in acidic solution, pointing out the role of protonation and the effect of the $\pi \pi^{*} / \mathrm{n} \pi^{*}$ coupling in the deactivation mechanism. ${ }^{10}$ In protonated aminopyridine $\left(\mathrm{APH}^{+}\right)$, the absence of $n_{n} \pi^{*}$ state should 
lead to rather simple deactivation mechanism, if any, involving out-of-plane ring deformation and amino bending modes. While these molecules are among the simplest aromatic ones with only one substituted functional group, other related systems such as aminobenzonitrile (ABN) and dimethyl aminobenzonitrile (DMABN) have shown to have particular excited state properties. In particular, when the amino group is in para position, charge transfer can occur leading to a $90^{\circ}$ twist motion of the amino group. ${ }^{11}$ The so-called twisted intramolecular charge transfer state (TICT) corresponds to a transition of an electron from lone pair orbital localized on the twisted amino group to the antibonding orbital on the aromatic cycle. Such TICT reaction has been observed in solution and small clusters due to the large stabilization of the charge transfer state upon solvation. Bare isolated molecules such as the chromophore of the green fluorescent protein ${ }^{12}$ and carbocyanine-like dye ${ }^{13}$ can undergo cis-trans photo isomerization in the absence of solvent. As it will be shown here, we have found evidence for TICT reaction in protonated 4-aminopyridine.

We here present the vibrationally resolved electronic spectra of cold, protonated 2-, 3- and 4aminopyiridine $\left(\mathrm{APH}^{+}\right)$along with their excited state lifetimes and dissociation kinetics through oneand two-color photofragmentation spectroscopy. One of the striking result is the absence of dissociation following electronic excitation around the band origin in $3-\mathrm{APH}^{+}$and $4-\mathrm{APH}^{+}$, while 2$\mathrm{APH}^{+}$does fragment. Geometry optimizations and frequency calculations have been performed at the coupled-cluster CC2 level in the ground and electronic states allowing a firm assignment of the excited state structures. In 4- $\mathrm{APH}^{+}$, a drastic competition in the excited state dynamics occurs within about $500 \mathrm{~cm}^{-1}$ above the band origin. Excited state calculations suggest that an intramolecular excited state proton transfer reaction competes with TICT formation, these reactions paths being discriminated by their fragmentation channels.

\section{Experimental Section}

The experimental setup has been previously presented ${ }^{14}$ and only a brief overview is described. The protonated ions are produced in an electrospray ion source (ESI) from a methanol solution at a concentration of $100 \mu \mathrm{M}$. The ions are stored in an octopole trap for $100 \mathrm{~ms}$ and extracted and accelerated at $220 \mathrm{~V}$ by applying a pulsed field at the exit lens of the octopole towards the second vacuum chamber where the quadrupole ion trap QIT (Jordan TOF, Inc.) is located. The 3D-QIT is housed in a copper box mounted on the cold head ( $\mathrm{CH}-204 \mathrm{~S}$, Sumitomo) of a compressed helium cryostat that maintained the temperature around 10-15 K. The incoming protonated aminopyridine $\mathrm{APH}^{+}$ions ( $\mathrm{m} / \mathrm{z}$ 95) are mass-selected before being trapped and thermalized through collisions with helium buffer gas introduced in the QIT by a pulsed valve (General valve, series 9 ) triggered a few ms 
before. The photodissociation laser is shined into the trap and both the parent and fragment ions are mass-analyzed in the linear time-of-flight mass spectrometer and detected with micro channel plates (Z Gap, Jordan TOF, Inc.). The electronic spectra are thus obtained by scanning the laser frequency and recording the signal of each fragment ion, normalized by the intensity of the laser and the parent ion signal.

Three types of electronic spectroscopy have been performed: (i) the vibrationally-resolved spectroscopy of the locally excited state $S_{1}$ through a 2-color excitation scheme (ii) the time-resolved dynamics of the excited states (from picosecond to microsecond time scale) (iii) the fragmentation kinetics on the millisecond time scale. Two sets of laser have been used. In Orsay, the photodissociation laser is the output of a mode-locked picosecond Nd:YAG laser (EKSPLA-SL300) operated at $10 \mathrm{~Hz}$ and pumping at $355 \mathrm{~nm}$ an optical parametric amplifier (EXSPLA-PG411) to obtain tunable visible/UV light in the 700-220 nm region. For the 2-color pump/probe experiments, the UV pump is issued from the OPA and the probe is the third harmonic of the Nd:YAG beam ( $355 \mathrm{~nm}$ ). The picosecond time resolved spectroscopy is recorded by delaying the probe beam with a motorized optical delay line with $6.6 \mathrm{ps}$ time step. Typical laser pulse energies are in the order of $50 \mu \mathrm{J}$ in the UV and $500 \mu \mathrm{J}$ for the $355 \mathrm{~nm}$ beam. Both beams are focused by a $700 \mathrm{~mm}$ lens and cross each other in the center of the trap. The cross correlation of the laser beams is about $16 \mathrm{ps}$. For the electronic spectrum, the photodissociation signal is averaged over 32 laser shots per wavelength step $(0.05 \mathrm{~nm}$ resolution) while for the 2-color experiments, a set of 5 scans of 16 laser shots per time step is averaged. In Marseille, the time resolved dynamics have been obtained with two nanosecond lasers (OPO EKSPLA-NT342B) delayed electronically in time. Finally, for the fragmentation kinetics measurement, the fragmentation time is recorded by changing the delay between the laser and the extraction pulse ejecting the ions from the ion trap to the time of flight. The time resolution, on the order of $100 \mathrm{~ns}$, is limited by the rise time of the high voltage pulser.

\section{Computational methods}

$A b$ initio calculations have been done with the TURBOMOLE program package (v6.3) ${ }^{15}$ making use of the resolution-of-identity approximation. ${ }^{16}$ The equilibrium geometries and the vibrational frequencies in the ground $S_{0}$ and excited electronic states $\left(S_{n}, T_{n}\right)$ have been calculated at the coupled-cluster CC2 level ${ }^{17}$ with the correlation-consistent polarized valence double-zeta aug-ccpVDZ basis set augmented with diffuse functions. ${ }^{18}$ The Franck-Condon analysis have been performed using PGOPHER software. ${ }^{19}$ 


\section{Results}

\section{Protonated 2-aminopyridine (2-APH $)$}

The photo dissociation mass spectra of 2-APH through 1- and 2-color excitation scheme are reported in Figure 1. The main fragmentation channel following UV excitation is at $\mathrm{m} / \mathrm{z} 78$, corresponding to $\mathrm{NH}_{3}$ loss. This fragment is the only one observed through low-energy collision induced dissociation (figure SI1 Supporting Information). The kinetics of formation of this photo fragment is rather long with a rising time of $450 \pm 50 \mu$ s (figure SI2 Supplementary Information). This is a strong indication that the $\mathrm{m} / \mathrm{z} 78$ ion is formed following UV excitation after internal conversion (IC) to the ground state. Other low intensity fragments are barely detected at m/z 94 (H loss), m/z 67, m/z 51 and m/z 41. These three latter ions are secondary fragments of the 2-AP radical cation $(\mathrm{m} / \mathrm{z} 94)$ as observed in the electron impact ionization mass spectrum. ${ }^{20,21}$ The fragmentation yield of these fragments is very weak through UV excitation. Interestingly, the fragmentation yield of the $\mathrm{H}$ loss channel and its secondary fragments is greatly increased through absorption of the $355 \mathrm{~nm}$ probe laser. Through the 2-color scheme (zero time delay between the pump and probe beams), all fragments are formed immediately after the laser excitation and the extraction of the ions from the QIT can be reduced to less than $1 \mu \mathrm{s}$. These results suggest that 2-APH fragments following UV excitation through IC leading to $\mathrm{m} / \mathrm{z} 78$ ions ( $\mathrm{NH}_{3}$ loss) associated with a fragmentation kinetics of $450 \mu \mathrm{s}$, and that the other fragmentation channels are all issued from a 2-photon excitation scheme (two UV photons or one UV photon $+355 \mathrm{~nm}$ photon).

The electronic spectra of 2- $\mathrm{APH}^{+}$, recorded on the $\mathrm{m} / \mathrm{z} 78$ ion through a 2-color scheme, are reported in Figure 1, starting from the band origin $\left(316.15 \mathrm{~nm}, 31631 \mathrm{~cm}^{-1}\right)$ up to $2500 \mathrm{~cm}^{-1}$ of excess energy in the excited state. In the lower right panel, the fragmentation time window is set at $1 \mu \mathrm{s}$ (prompt dissociation), i. e. the lasers being shined $1 \mu \mathrm{s}$ before the extraction of the ions from the QIT. In that case, the spectra recorded on all fragmentation channels (including $\mathrm{H}$ loss and its secondary fragments) are identical. The band origin and the first vibrations located at +80 and $+160 \mathrm{~cm}^{-1}$ have very weak intensities (see the inset in Fig.1, lower right panel). Other weak intensity transitions are observed at $+335 \mathrm{~cm}^{-1}$ and about $+500 \mathrm{~cm}^{-1}$. At $+635 \mathrm{~cm}^{-1}$ and above, sharp bands are detected that are ten times more intense than the band origin. As will be explained below, they are assigned to vibrational progressions in a second minimum of the excited state potential energy surface with large Franck Condon activity. They are located at $+157,380,498,547,797$ and $957 \mathrm{~cm}^{-1}$ from the first intense band at $635 \mathrm{~cm}^{-1}$. Above $c a .+2000 \mathrm{~cm}^{-1}$ of excess energy in the excited state, no other sharp 
vibronic transition is detected. The band origin of $2-\mathrm{APH}^{+}$is red-shifted by more than $1800 \mathrm{~cm}^{-1}$ as compared to neutral 2-AP, ${ }^{22}$ that has an intense band origin at $33471 \mathrm{~cm}^{-1}$ with active modes at 245 $\mathrm{cm}^{-1}$ and $316 \mathrm{~cm}^{-1}$ (out-of-plane modes $10 \mathrm{~b}_{0}{ }^{1}, 16 \mathrm{a}_{0}{ }^{1}$ ) and 526, 826 and $953 \mathrm{~cm}^{-1}$ (in-plane ring deformations $6 a_{0}{ }^{1}, 1_{0}{ }^{1}$ and $12_{0}{ }^{1}$ ).
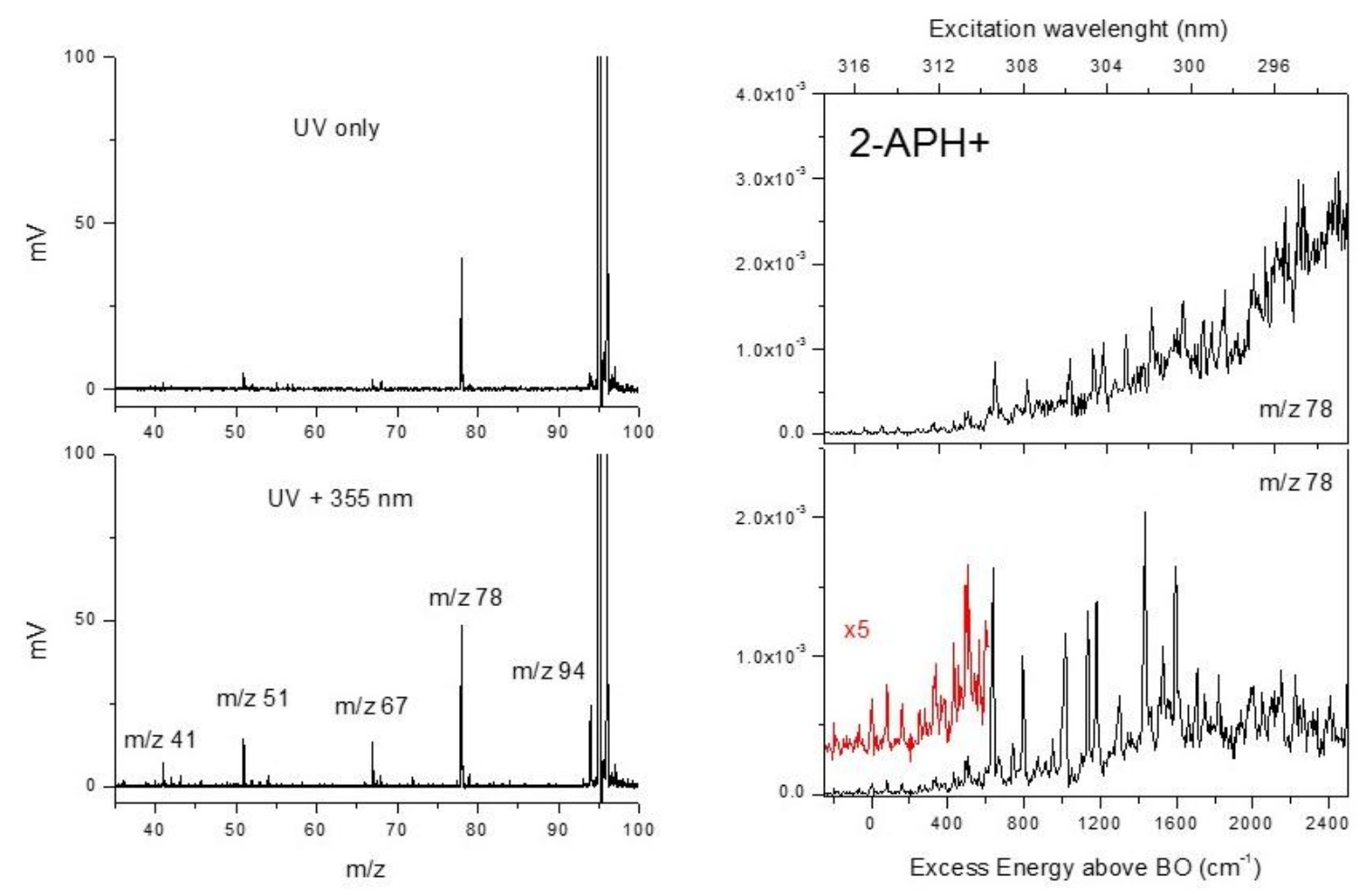

Figure 1: (Left) Photo dissociation mass spectra of 2-APH $(\mathrm{m} / \mathrm{z} 95)$. Upper panel, UV only, one fragment at $\mathrm{m} / \mathrm{z} 78$ ( $\mathrm{NH}_{3}$ loss). Lower panel, 2-color (pump UV + probe $355 \mathrm{~nm}$ ) excitation scheme. (Right) 2-color photo dissociation spectra recorded on the $\mathrm{m} / \mathrm{z} 78$ ionic fragment $\left(\mathrm{NH}_{3}\right.$ loss): lower panel, fragmentation time window of $1 \mu \mathrm{s}$. The band origin located at $316.15 \mathrm{~nm}$ is very weak. Upper panel, fragmentation time window of $10 \mathrm{~ms}$. The background signal is due to fragmentation induced by the UV only.

The spectrum reported in the upper right panel is obtained at much longer fragmentation time window, ca. $10 \mathrm{~ms}$. As it can be clearly seen, a broad background signal is clearly observed that increases with the excess energy in the excited state. There is no clear onset of this continuous underlying band although it is noteworthy that the absence of sharp vibronic transitions above 2000 $\mathrm{cm}^{-1}$ (around $298 \mathrm{~nm}$ ) coincides with its large increase. The unstructured band is only detected for the $\mathrm{m} / \mathrm{z} 78$ fragmentation channel $\left(\mathrm{NH}_{3}\right.$ loss), and indeed corresponds to fragmentation following UV excitation only (1-color scheme). Two fragmentation mechanisms thus seem to be in competition. Around the band origin, sharp vibronic transitions are observed. About $2000 \mathrm{~cm}^{-1}$ higher in energy, a broad fragmentation continuum appears through 1-color excitation and is observed only for the $\mathrm{m} / \mathrm{z}$ 78 ion. 


\section{Protonated 3-aminopyridine (3-APH $)$}
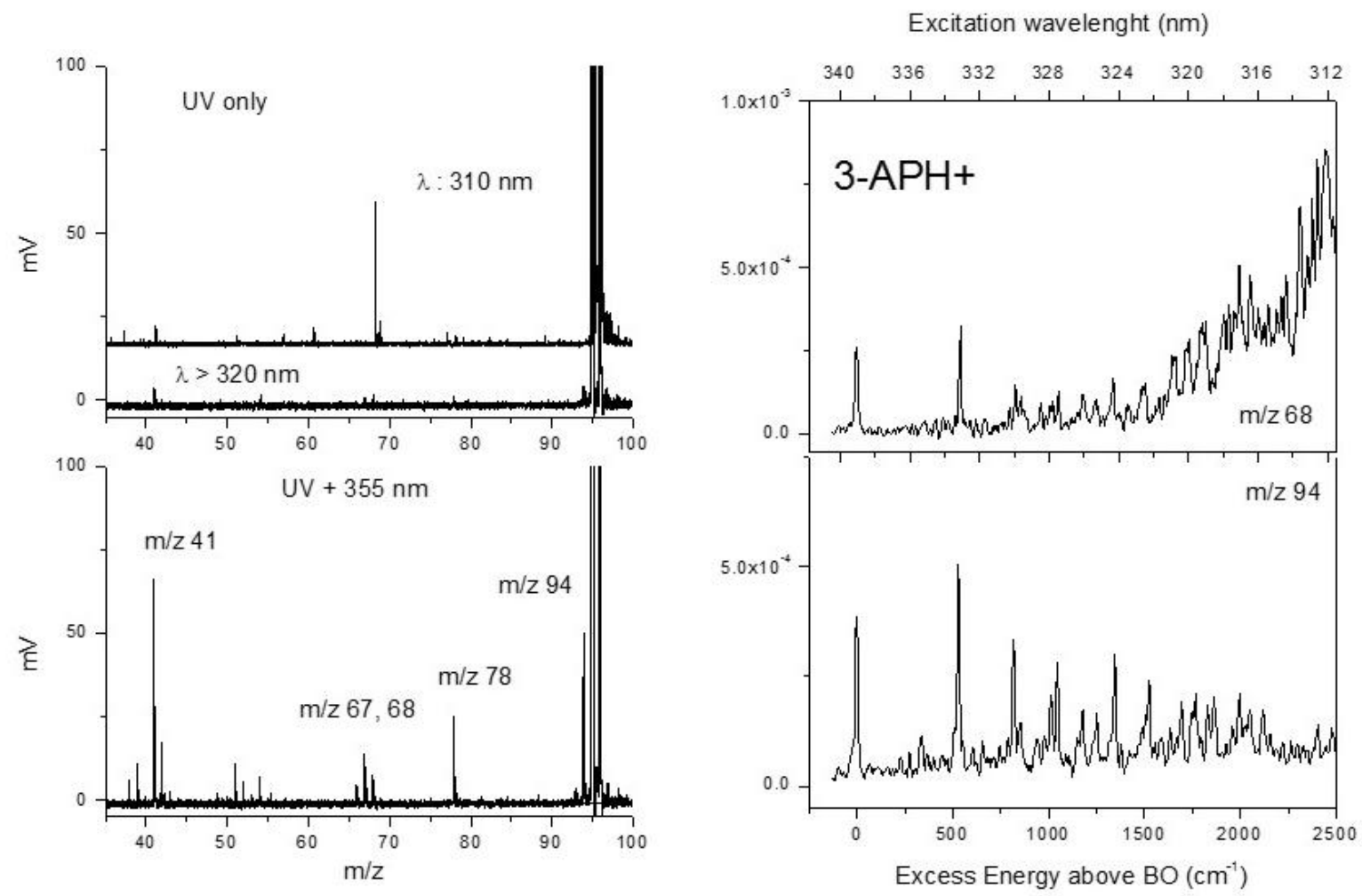

Figure 2: (Left) Photo dissociation mass spectra of $3-\mathrm{APH}^{+}(\mathrm{m} / \mathrm{z}$ 95). Upper panel, UV only: no fragmentation for $\lambda>320 \mathrm{~nm}, \mathrm{~m} / \mathrm{z} 68$ (HCN loss) for $\lambda<320 \mathrm{~nm}$. Lower panel, 2-color (UV $+355 \mathrm{~nm}$ ) excitation scheme. (Right) 2-color photodissociation spectra of $3-\mathrm{APH}^{+}$with the fragmentation time window of $10 \mathrm{~ms}$ recorded on the $\mathrm{m} / \mathrm{z} 94$ ionic fragment ( $\mathrm{H}$ loss channel) and $\mathrm{m} / \mathrm{z} 68$ fragment (HCN loss channel). The band origin is at $339.05 \mathrm{~nm}$. The onset of the background signal observed only on the $\mathrm{m} / \mathrm{z} 68$ fragment starts at about $322 \mathrm{~nm}$ (from $+1500 \mathrm{~cm}^{-1}$ above the origin).

The mass spectra of 3- $\mathrm{APH}^{+}$obtained through 1- and 2-color photofragmentation schemes are reported on the left part of Figure 2 together with the 2-color photofragmentation spectrum from the band origin ( $339.05 \mathrm{~nm}, 29494 \mathrm{~cm}^{-1}$ ) up to $2500 \mathrm{~cm}^{-1}$ of excess energy (Figure 2 right). The striking result is the zero photo-fragmentation yield following 1-color excitation (UV only) around the band origin $(\lambda>320 \mathrm{~nm})$. However, fragments are detected in a 2-color scheme in that spectral region, which indicates that the UV pump photon is effectively absorbed but does not lead to any fragmentation. Through 2-color excitation, several mass peaks are observed at $\mathrm{m} / \mathrm{z} 94$ (H loss), m/z $78\left(\mathrm{NH}_{3}\right.$ loss $)$ and other low mass fragments that are all promptly formed after the laser excitation (less than $1 \mu$ s fragmentation time). The radical cation of 3-AP $(\mathrm{m} / \mathrm{z} 94)$ is detected along with its secondary fragments at masses $\mathrm{m} / \mathrm{z} 67$ (HCN loss) and $\mathrm{m} / \mathrm{z} 41 \cdot{ }^{20,21} \mathrm{HCN}$ loss is also detected at $\mathrm{m} / \mathrm{z} 68$ which is the main fragment produced in CID (figure SI1, supporting Information). Interestingly, this $\mathrm{m} / \mathrm{z} 68$ fragment is the only ion formed through 1-color UV excitation with high excess energy $(\lambda<$ 
$320 \mathrm{~nm}$ ). Its fragmentation kinetics is rather long, about $2 \pm 0.1 \mathrm{~ms}$, emphasizing that dissociation through UV excitation only occurs after internal conversion to the ground state (See figure SI2 Supporting Information).

In the lower right panel of Figure 2, the photofragmentation yield on $\mathrm{m} / \mathrm{z} 94$ fragment ion $(\mathrm{H}$ loss) is reported and shows well resolved vibronic transitions from the band origin up to $1500 \mathrm{~cm}^{-1}$ of excess energy. Note that the spectra recorded on all the other fragmentation channels, except the HCN loss channel ( $\mathrm{m} / \mathrm{z} 68)$, are identical. The spectrum recorded on this latter channel is reported in the upper right panel. There is an underlying background signal starting about $+1500 \mathrm{~cm}^{-1}$ above the origin, which is indeed induced by UV excitation only. There is a clear change in the deactivation process following UV excitation from this excess energy. While no fragmentation happens around the band origin, internal conversion opens around $1500 \mathrm{~cm}^{-1}$ of excess energy in the $S_{1}$.

The electronic spectrum of $3 \mathrm{APH}^{+}$shows well-resolved vibronic transitions up to $1500 \mathrm{~cm}^{-1}$ where the onset of the background signal roughly appears. $3-\mathrm{APH}^{+}$has an intense $0_{0}{ }^{0}$ band with other vibronic transitions located at $+527 \mathrm{~cm}^{-1}$ and $813 \mathrm{~cm}^{-1}$. These two transitions can be assigned to inplane ring deformation modes $6 \mathrm{a}_{0}{ }^{1}$ and $1_{0}{ }^{1}$, as observed in the neutral aminopyridine molecule. ${ }^{23}$ There is a set of bands at 975, 1007 and $1040 \mathrm{~cm}^{-1}$ followed by two next intense bands at $1341 \mathrm{~cm}^{-1}$ and $1518 \mathrm{~cm}^{-1}$. No low frequency mode is observed at the band origin, in contrast to $2-\mathrm{APH}^{+}$, the first two transitions being at $276 \mathrm{~cm}^{-1}$ and $334 \mathrm{~cm}^{-1}$ with rather weak intensity. The band origin of the protonated molecule is largely red-shifted by more than $3500 \mathrm{~cm}^{-1}$ as compared to the neutral form but the overall spectrum is similar, in particular the intense 6a and 1 vibrational transitions.

\section{Protonated 4-aminopyridine (4-APH $\left.{ }^{+}\right)$}

The photo fragmentation mass spectra of $4-\mathrm{APH}^{+}$through 1- and 2-color excitation schemes are reported in Figure 3 along with its electronic spectrum. As for $3-\mathrm{APH}^{+}$, the UV fragmentation yield is null at the band origin $\left(269 \mathrm{~nm}, 37174 \mathrm{~cm}^{-1}\right)$ and dramatically increases though absorption of the $355 \mathrm{~nm}$ probe laser. The 2-color fragmentation channels are essentially the same as before, i.e. $\mathrm{m} / \mathrm{z}$ 94 ( $\mathrm{H}$ loss) and its three secondary fragments at $\mathrm{m} / \mathrm{z} 67,51,41, \mathrm{~m} / \mathrm{z} 78$ ( $\mathrm{NH}_{3}$ loss) and $\mathrm{m} / \mathrm{z} 68$ (HCN loss), with one exception, a new fragmentation channel appearing at $\mathrm{m} / \mathrm{z} 79$. This ionic fragment is associated to the loss of $\mathrm{NH}_{2}$ from the protonated molecule and is specific of 4-APH . For wavelengths below $265 \mathrm{~nm}$, two fragments at masses $\mathrm{m} / \mathrm{z} 68$ and $\mathrm{m} / \mathrm{z} 78$ are produced following UV only excitation. These two ions are the ones formed in CID (Figure SI1, Supporting Information). Their fragmentation kinetics is similar, about $3.3 \pm 0.2 \mathrm{~ms}$, which indicates that these two ions are issued from a statistical fragmentation process in the ground electronic state after internal conversion. In 4- 
$\mathrm{APH}^{+}$, fragmentation following internal conversion opens from roughly $500 \mathrm{~cm}^{-1}$ of excess energy in the $S_{1}$ while no fragmentation is observed through UV excitation at the band origin.
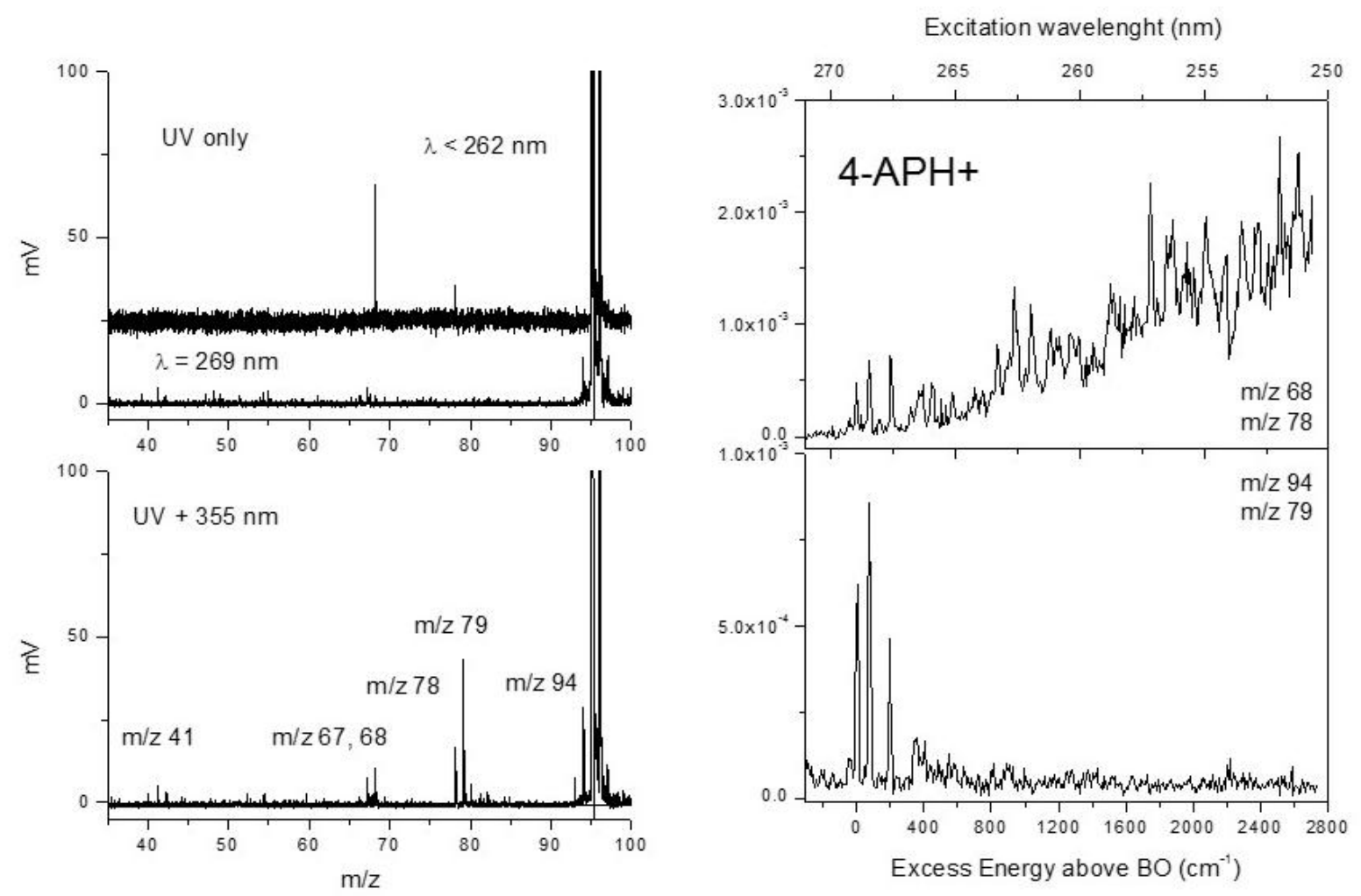

Figure 3: (Left) Photo dissociation mass spectra of 4-APH (m/z 95). Upper panel, UV only, no fragmentation for $\lambda>265 \mathrm{~nm}$, mostly $\mathrm{m} / \mathrm{z} 68$ (HCN loss) for $\lambda<265 \mathrm{~nm}$. Lower panel, 2 colors (UV + $355 \mathrm{~nm}$ ) excitation scheme. (Right) 2-color photo dissociation spectra of 4- $\mathrm{APH}^{+}$with the fragmentation time window of $10 \mathrm{~ms}$ recorded (lower panel) on the $\mathrm{m} / \mathrm{z} 94$ ( $\mathrm{H}$ loss) and $\mathrm{m} / \mathrm{z} 79\left(\mathrm{NH}_{2}\right.$ loss) ionic fragments and (upper panel) on the $\mathrm{m} / \mathrm{z} 68$ ( $\mathrm{HCN}$ loss) and $\mathrm{m} / \mathrm{z} 78$ ( $\mathrm{NH}_{3}$ loss). The band origin is at $269 \mathrm{~nm}$. The 2-color signals recorded on m/z 94 and $\mathrm{m} / \mathrm{z} 79$ vanish from $500 \mathrm{~cm}^{-1}$ above the origin in conjunction with the onset of the 1-color background signal observed only on $\mathrm{m} / \mathrm{z} 78$ and $\mathrm{m} / \mathrm{z} 68$ ionic fragments.

The electronic spectrum of 4- $\mathrm{APH}^{+}$is reported in Figure 3 (right panel) from the band origin up to $2600 \mathrm{~cm}^{-1}$ of excess energy. The band origin is dramatically blue-shifted as compared to the neutral molecule by more than $3000 \mathrm{~cm}^{-1} .{ }^{24}$ This is in contrast with the large red shift observed in the case of 2- and 3-APH ${ }^{+}$. Besides, the excitation spectrum strongly depends on the fragmentation channel. All the fragments produced only through 2 -color excitation scheme, i. e. $\mathrm{m} / \mathrm{z} 94, \mathrm{~m} / \mathrm{z} 79$, $\mathrm{m} / \mathrm{z} 67$ and $\mathrm{m} / \mathrm{z} 41$, exhibit sharp vibronic transitions at $76 \mathrm{~cm}^{-1}, 195 \mathrm{~cm}^{-1}$ and $350 \mathrm{~cm}^{-1}$ in a very narrow spectral region above the origin. Above about $500 \mathrm{~cm}^{-1}$ of excess energy, the 2-color fragmentation yield on these fragments vanishes (Figure 3, lower layer). At this excess energy in the 
excited state, a 1-color signal opens on masses $\mathrm{m} / \mathrm{z} 78$ and $\mathrm{m} / \mathrm{z} 68$, evidenced by the increasing background signal (Figure 3, upper layer). Some sharp transitions are superimposed on the background signal, at $808 \mathrm{~cm}^{-1}, 910 \mathrm{~cm}^{-1}$ and $1005 \mathrm{~cm}^{-1}$ along with their combination bands, but the signal-to-background ratio is quite low. These frequencies match the $1_{0}{ }^{1}$ and $12_{0}{ }^{1}$ in-plane ring modes observed in the other amino pyridine molecules (either in neutral or protonated forms).

The electronic spectrum of 4- $\mathrm{APH}^{+}$recorded on the $\mathrm{m} / \mathrm{z} 94$ ionic fragment ( $\mathrm{H}$ loss channel) through a 2-color scheme is clearly different from the spectra recorded in the case of 2- and 3-APH . Only a few low frequency modes are observed. The 1-color fragmentation signal starts only $500 \mathrm{~cm}^{-1}$ above the band origin and becomes the unique deactivation mechanism as the excess energy increases. Besides, a new ionic fragment $(\mathrm{m} / \mathrm{z} 79)$ associated to the loss of $\mathrm{NH}_{2}$ from the protonated molecule is formed in the 2-color photo dissociation scheme. However, its pump/probe transient signal differs from the one recorded on the $\mathrm{H}$ loss channel, as shown in Figure 4.
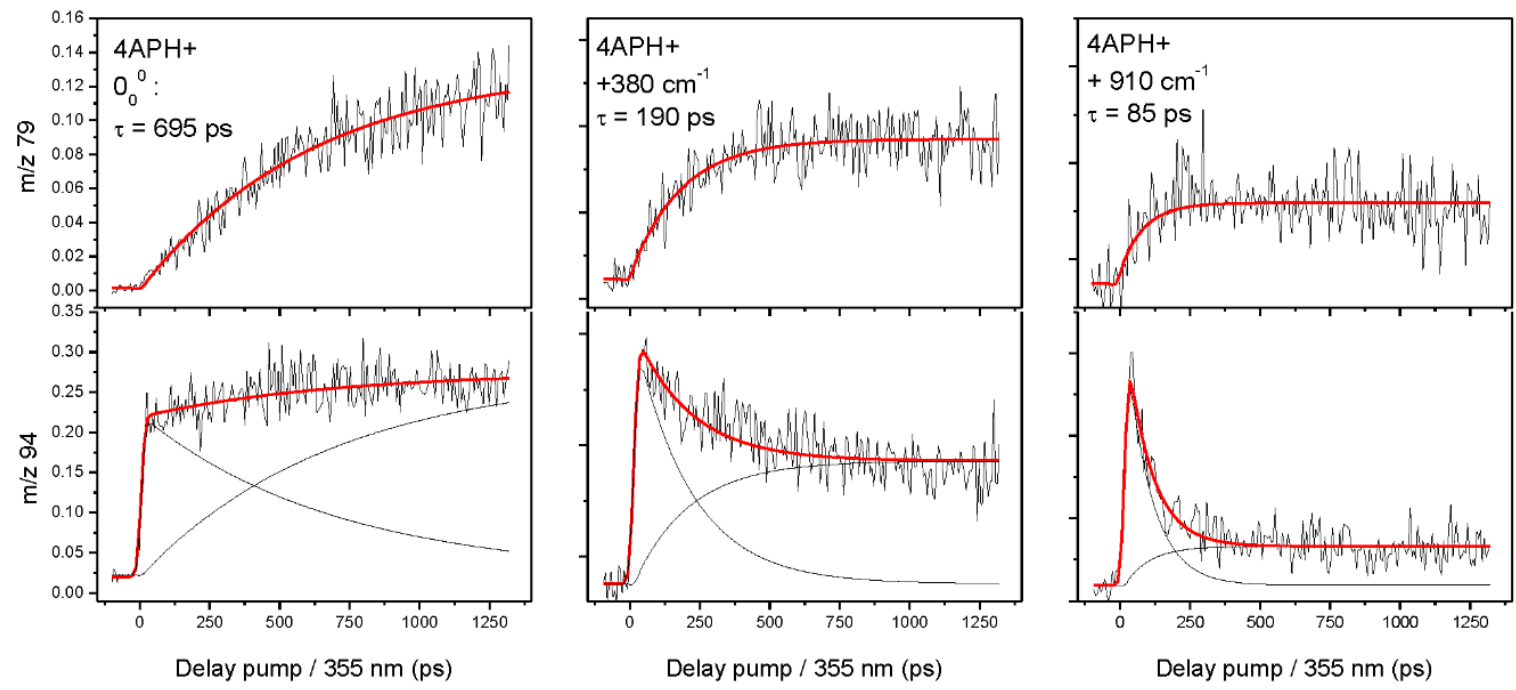

Figure 4: Pump/probe signals recorded on two fragmentation channels $(\mathrm{m} / \mathrm{z} 79$, top and $\mathrm{m} / \mathrm{z} 94$ bottom) for three excitation energies (pump) for $4-\mathrm{APH}^{+}$. For each excitation energy, the two transient signals are fitted with the same time constant $\tau$ in two exponential functions (growth and decay functions).

The excited state lifetime of 4-APH has been recorded as a function of the excitation energy. The time dependent 2-color signal depends on the fragmentation channel. The $\mathrm{m} / \mathrm{z} 79$ fragment exhibits a mono exponential rising signal as a function of the pump/probe delay. The fitted time constant decreases as the excess energy increases, from $695 \pm 50 \mathrm{ps}$ at the band origin down to $85 \pm$ 
$10 \mathrm{ps}$ at $910 \mathrm{~cm}^{-1}$. This exponential growth signal is a clear signature of a population created by the UV pump laser that evolves towards another excited state which can be probed through absorption of the $355 \mathrm{~nm}$ laser to produce the $\mathrm{m} / \mathrm{z} 79$ ionic fragment. It is noteworthy that this fragment is not formed at short pump/probe delay, so it cannot be associated with the absorption of the probe laser from the locally excited $\pi \pi^{*}$ state. It is thus concluded that the time constant of the exponential growth function is indeed the $\pi \pi^{*}$ excited state lifetime of $4-\mathrm{APH}^{+}$. The evolution of the $\pi \pi^{*}$ excited state lifetime of 2-, 3- and 4- $\mathrm{APH}^{+}$as a function of the excess energy are plotted in Figure 5. While the three molecules follow a quasi linear variation of the lifetime with excess energy, the 4-APH excited state lifetime is 1 and 2 orders of magnitude shorter as compared to 3 - and 2-APH, respectively. It is worth mentioning that the 2 -color signal recorded on the $\mathrm{m} / \mathrm{z} 79$ ionic fragment stays constant even at the longest pump/probe delay available with the optical delay line. Long timescale pump/probe experiments have been performed with nanosecond lasers and using electronic delays between the lasers and the transient recorded on the $\mathrm{m} / \mathrm{z} 79$ fragment exhibits a mono exponential decay of $2.0 \pm 0.1 \mu$ s (Figure 5). This $2 \mu$ s time constant is assigned to the lifetime of a second excited state populated from the $\pi \pi^{*}$ excited state, that absorbs the probe laser to give the specific $\mathrm{m} / \mathrm{z} 79$ ionic fragment.
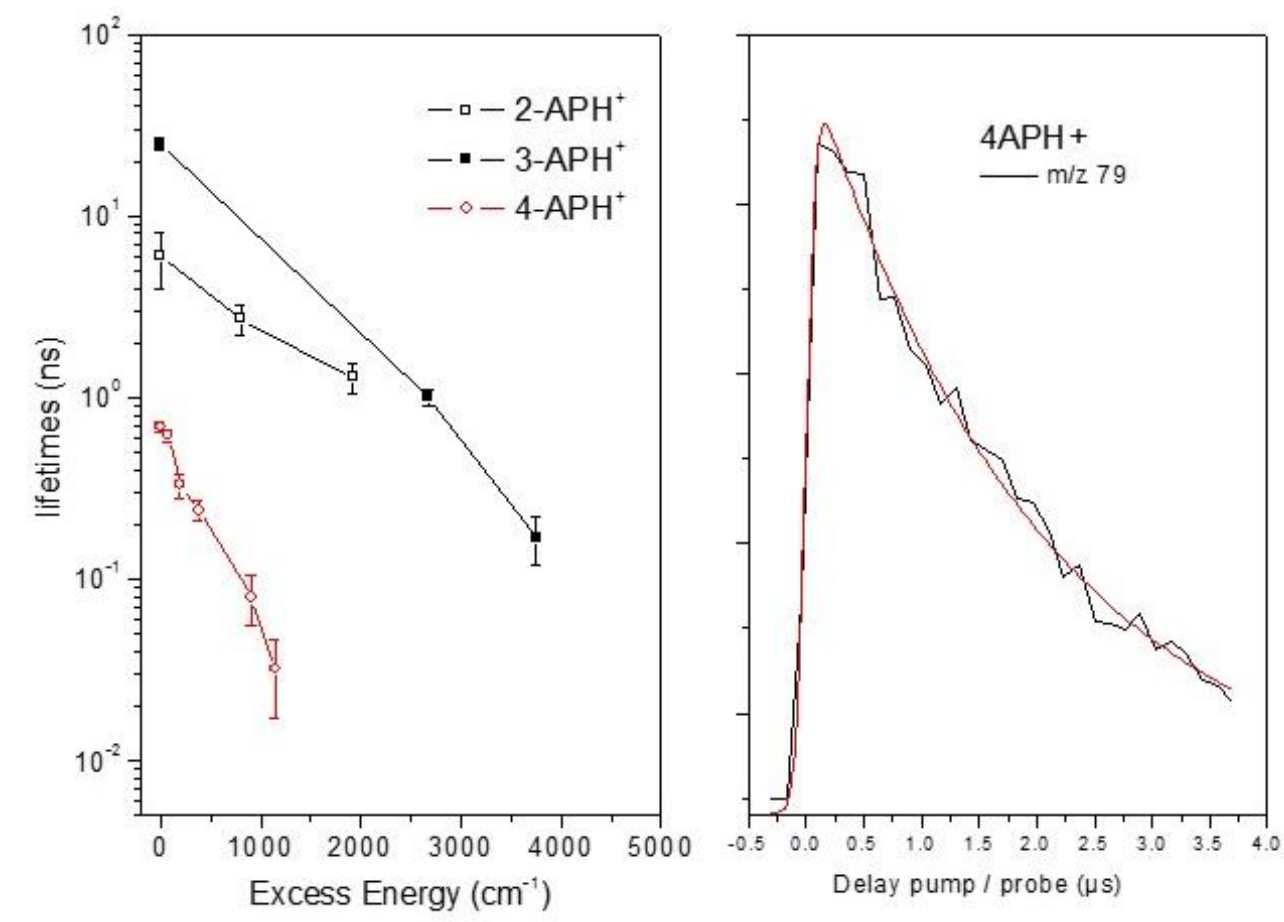

Figure 5: (Left) Evolution of the excited state lifetimes of 2-APH $\mathrm{AP}^{+}, 3-\mathrm{APH}^{+}$and 4-APH ${ }^{+} \mathrm{y}$ log scale) as the function of the excess energy in the $S_{1}$ state. (Right) transient recorded on the $\mathrm{m} / \mathrm{z} 79$ ionic fragment of $4-\mathrm{APH}^{+}$for long pump/probe delay ( $\mu \mathrm{s}$ scale). The transient is fitted by a mono exponential decay function with $2 \mu$ s time constant. 
The pump/probe signal recorded on the $\mathrm{H}$ loss channel shows a quite different time evolution with the excess energy. At the band origin, the signal increases within the cross-correlation of the laser beams and slightly increases with the time delay. For larger excitation energy, the time evolution exhibits a mono exponential decay but does not go down to zero (background UV signal only). The constant signal at long delay time decreases in intensity as the excess energy increases, exactly as the exponential growth signal recorded on the $\mathrm{m} / \mathrm{z} 79$ ion. Since these two fragmentation channels exhibit exactly the same excitation spectrum through the 2-color photo dissociation scheme, one can confidently assume that the time evolution recorded on the $\mathrm{H}$ loss channel is indeed issued from the sum of an exponential growth function (absorption from the long lived excited state) and exponential decay function (absorption from the $\pi \pi^{*}$ ) with the same time constant assigned to the $\pi \pi^{*}$ excited state lifetime. At the band origin, the weight of each function is similar, leading to a step-like function, while at higher excitation energy, the exponential rising signal vanishes (as observed for the $\mathrm{m} / \mathrm{z} 79$ ion) leading to an predominant exponential decay signal. At variance with the $\mathrm{m} / \mathrm{z} 79$ ionic fragment, the $\mathrm{H}$ loss channel is produced through absorption of the $355 \mathrm{~nm}$ probe laser during all the dynamics.

\section{Discussion}

\section{Vertical and adiabatic excited state calculations}

Table 1: vertical transition energies (eV) of 2-3- and 4- $\mathrm{APH}^{+}$(CC2/aug-cc-pVDZ). In bold, $\pi \pi^{*}$ transition bearing the oscillator strength for UV excitation. All energies in eV.

\begin{tabular}{|c|c|c|c|c|c|}
\hline \multicolumn{2}{|l|}{$2-\mathrm{APH}^{+}\left(\mathrm{C}_{\mathrm{s}}\right)$} & \multicolumn{2}{|l|}{$3-\mathrm{APH}^{+}\left(\mathrm{C}_{\mathrm{s}}\right)$} & \multicolumn{2}{|l|}{$4-\mathrm{APH}^{+}\left(\mathrm{C}_{2 \mathrm{v}}\right)$} \\
\hline Elec. conf. & $\mathrm{eV}$ & Elec. Conf. & $\mathrm{eV}$ & Elec. Conf. & $\mathrm{eV}$ \\
\hline$\pi \pi^{*}\left(A^{\prime}\right)\left(4 a^{\prime \prime}-5 a^{\prime \prime}\right)$ & 4.49 & $\pi \pi^{*}\left(A^{\prime}\right)\left(4 a^{\prime \prime}-5 a^{\prime \prime}\right)$ & 3.98 & $\pi \pi^{*}\left(\mathrm{~A}_{1}\right)\left(3 \mathrm{~b}_{2}-4 \mathrm{~b}_{2}\right)$ & 5.11 \\
\hline$\pi \pi *\left(A^{\prime}\right)\left(4 a^{\prime \prime}-6 a^{\prime \prime}\right)$ & 5.84 & $\pi \pi *\left(A^{\prime}\right)\left(4 a^{\prime \prime}-6 a^{\prime \prime}\right)$ & 5.19 & $\pi \pi *\left(\mathrm{~B}_{1}\right)\left(3 \mathrm{~b}_{2}-2 \mathrm{a}_{2}\right)$ & 5.13 \\
\hline$\pi \sigma_{N H} *\left(A^{\prime \prime}\right)\left(4 a^{\prime \prime}-22 a^{\prime}\right)$ & 6.23 & $\pi \sigma_{N H} *\left(A^{\prime \prime}\right)\left(4 a^{\prime \prime}-22 a^{\prime}\right)$ & 6.13 & $\pi \pi *\left(B_{1}\right)\left(1 a_{2}-4 b_{2}\right)$ & 6.30 \\
\hline$\pi \pi *\left(A^{\prime}\right)\left(3 a^{\prime \prime}-5 a^{\prime \prime}\right)$ & 7.00 & $\pi \pi *\left(A^{\prime}\right)\left(3 a^{\prime \prime}-5 a^{\prime \prime}\right)$ & 6.29 & $\pi \sigma_{N H} *\left(B_{2}\right)\left(3 b_{2}-14 a_{1}\right)$ & 6.71 \\
\hline$\pi \sigma_{N H 2} *\left(A^{\prime \prime}\right)\left(4 a^{\prime \prime}-23 a^{\prime}\right)$ & 7.18 & $\pi \sigma_{\mathrm{NH} 2} *\left(\mathrm{~A}^{\prime \prime}\right)\left(4 \mathrm{a}^{\prime \prime}-23 \mathrm{a}^{\prime}\right)$ & 6.49 & $\pi \sigma_{\mathrm{NH} 2} *\left(\mathrm{~B}_{2}\right)\left(3 \mathrm{~b}_{2}-15 \mathrm{a}_{1}\right)$ & 7.11 \\
\hline
\end{tabular}

$A b$ initio coupled-cluster (CC2/aug-cc-pVDZ) calculations have been performed for the three protonated aminopyridine. Ground state geometry optimizations confirm that, for all these molecules, protonation occurs at the pyridinic nitrogen (noted $\mathrm{NH}^{+}$isomer). Protonation at the amino group and carbon atoms is in average 0.8 and $1.5 \mathrm{eV}$ higher in energy. For all molecules, the ground state equilibrium structure is planar without pyramidalization of the amino group, at variance with what is found for the neutral species. ${ }^{22-24} 2$ - and 3-APH thus belong to $\mathrm{Cs}$ point group and 4- $\mathrm{APH}^{+}$ 
belongs to $C_{2 v}$ point group. The vertical excited state energies are reported in Table 1 along with the corresponding frontier molecular orbital representation.

As it can be readily seen in Table 1 , in 2- and 3- $\mathrm{APH}^{+}$, the first $\pi \pi^{*}$ excited state $\mathrm{S}_{1}\left(\mathrm{~A}^{\prime}\right)$ bears the oscillator strength for UV excitation while other excited states, either of $A^{\prime}$ or $A^{\prime \prime}$ symmetry, are much higher in energy. The $A^{\prime \prime}$ transitions correspond to dissociative $\pi \sigma^{*}$ states, with diffuse Rydberg type orbitals either on the pyridinic site $\mathrm{NH}$ or the amino group $\mathrm{NH}_{2}$. These charge transfer states are calculated about $2 \mathrm{eV}$ above the singlet ${ }^{1} \pi \pi^{*}$ and are not thought to be involved in the photo dynamics of the protonated molecule following UV excitation. In these protonated aminopyridine, the lone pair of the pyridinic nitrogen is involved in the bonding with the proton, so there is no $n_{N} \pi^{*}$ state as in the neutral form. In these planar ground state structures, the lone pair of the amino group ( $p_{z}$ orbital) is in the same plane as the $\pi$ orbitals of the pyridine ring and contributes to the $\pi \pi^{*}\left(A^{\prime}\right)$ transition. The situation is a little more complex in 4- $\mathrm{APH}^{+}$since two low-lying $\pi \pi^{*}$ states of different symmetry $\left(A_{1}\right.$ and $\left.B_{1}\right)$ are quasi degenerated. However, the $A_{1}$ state has an oscillator strength 40 times larger than the $B_{1}$ state and is populated through UV excitation. Otherwise, as for the other molecules, the dissociative $\pi \sigma^{*}\left(A^{\prime \prime}\right)$ states lie much higher in energy and should not be involved in the deactivation mechanism following UV excitation.

Geometry optimizations of the first $\pi \pi^{*}$ state have been performed for the three molecules. The adiabatic $S_{1}$ energies, compared to the experimental band origin transitions are reported in Table 2 and the optimized structures are plotted in Figure 6 . We first present the analysis of the electronic excitation spectra and fragmentation mechanism of 2- and 3- $\mathrm{APH}^{+}$and then discuss the more complicated behavior of 4-APH .

Table 2: Experimental and calculated $\pi \pi^{*}$ energy transitions of 2- 3- and 4- $\mathrm{APH}^{+}$. Calculated energy transitions (CC2/aug-cc-pVDZ) corrected by the difference of ZPE between the ground and excited states. All values in eV.

\begin{tabular}{ccccc}
\hline Molecules & Symmetry & $0_{0}{ }^{0}$ calc & $0_{0}{ }^{0}$ exp & $\Delta$ exp-calc \\
\hline 2-APH & no sym & 4.00 & 3.92 & -0.08 \\
& planar Cs & 4.02 & 4.00 & -0.02 \\
$3-\mathrm{APH}^{+}$ & planar Cs & 3.60 & 3.65 & +0.05 \\
4-APH & in-plane $\mathrm{NH}_{2}$ & 4.58 & 4.61 & +0.03 \\
& twisted $\mathrm{NH}_{2}$ & $4.20^{a}$ & & +0.41 \\
\hline
\end{tabular}

\footnotetext{
${ }^{\mathrm{a}} \pi \sigma_{\text {arom }}{ }^{*}\left(\mathrm{~A}^{\prime \prime}\right)$ state
} 

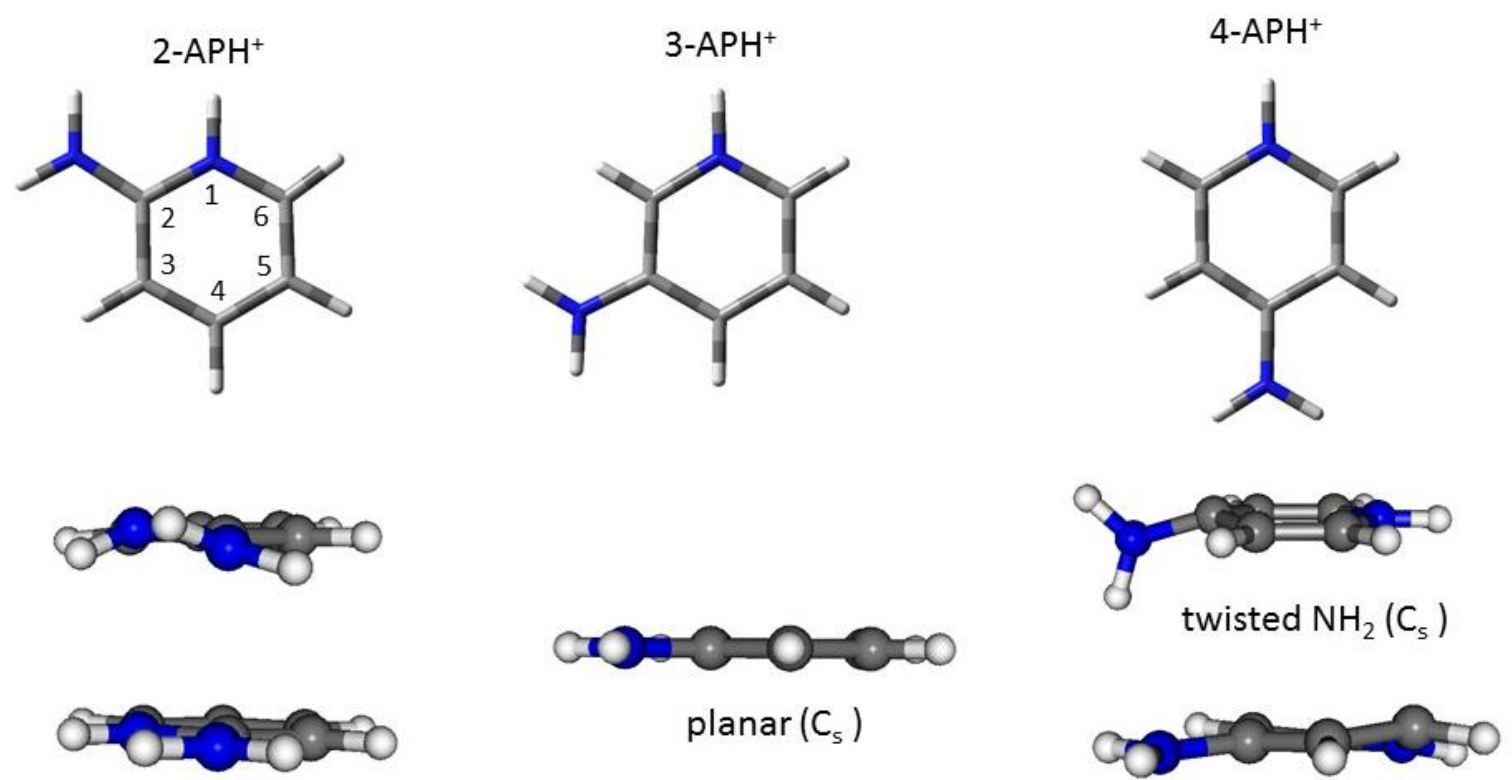

planar $\left(C_{s}\right)$

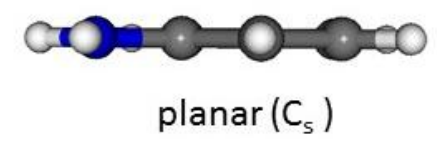

In-plane $\mathrm{NH}_{2}$

Figure 6: Optimized structures of 2- $\mathrm{APH}^{+}, 3-\mathrm{APH}^{+}$and 4- $\mathrm{APH}^{+}$in $\mathrm{S}_{0}$ (top) and $\mathrm{S}_{1}$ states. In the twisted structure of $4-\mathrm{APH}^{+}$, the mirror plane of the $\mathrm{Cs}$ point group comprises the amino moiety and is perpendicular to the aromatic ring.

\section{Franck-Condon analysis}

\section{2- $\mathrm{APH}^{+}$}

The weak intensity of the band origin along with the progression on low frequency modes reveals a geometry change in the excited state as predicted by the excited state optimized structure calculated at the CC2/aug-cc-pVDZ. Geometry optimization (see Figure 6) of the first excited state leads to pyramidalization of the ring nitrogen (dihedral angle $\mathrm{CCNH}^{+}{ }^{\circ} 0^{\circ}$ ) along with a slight out-of-plane twist motion of the amino group (dihedral angle $\mathrm{NCNH}_{\text {amino }} 10^{\circ}$ ). The adiabatic transition energy including ZPE difference correction is $4.00 \mathrm{eV}$, in very good agreement with the experimental band origin of $3.92 \mathrm{eV}$, i.e. only $0.08 \mathrm{eV}$ higher (see Table 2). Besides, the $\mathrm{S}_{2}$ adiabatic transition energy is calculated at $5.45 \mathrm{eV},(227.5 \mathrm{~nm})$ and closely matches the onset of a second intense band seen in the large spectral range spectrum (See figure SI3 in Supporting Information). In figure 7, the simulated Franck Condon spectrum is reported and compared to the experimental spectrum. The origin of the calculated spectrum is set to the first observed transition. The calculated spectrum reproduced the main vibronic transitions up to the intense band at $635 \mathrm{~cm}^{-1}$ which is clearly absent from the simulation. In this region, the active modes are out-of-plane vibrations of the $\mathrm{NH}_{2}$ and $\mathrm{NH}$ groups at 
$80,347,486$ and $509 \mathrm{~cm}^{-1}$. The in-plane ring deformation 6a and 1 modes are calculated at 379 and $795 \mathrm{~cm}^{-1}$, respectively. Neither a specific mode nor combination bands can account for the $635 \mathrm{~cm}^{-1}$ transition and the other intense bands seen in the experimental spectrum.

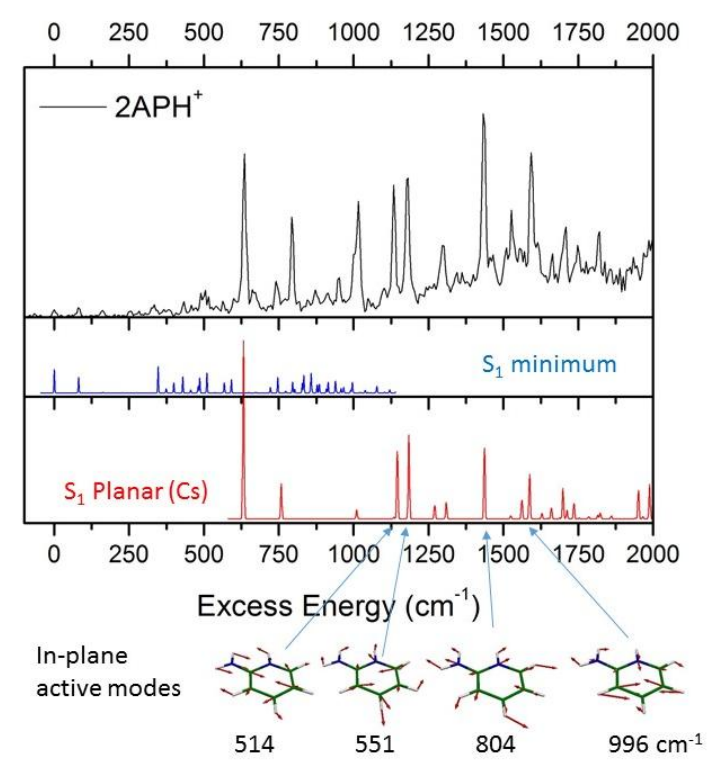

Figure 7: Comparison of the experimental (top) and the Franck-Condon simulated spectra of 2-APH ${ }^{+}$ of the two minima on the potential energy surface $S_{1}$. Middle (blue): adiabatic minimum (origin at 0 ) with twist $\mathrm{NH}_{2}$ group and pyramidalization of the pyridinic nitrogen. Bottom (red): planar symmetry (Cs point group) with $0_{0}{ }^{0}$ at $+635 \mathrm{~cm}^{-1}$. The two spectra are plotted with the same vertical scale.

Since no other conformer is expected in the ground state, we have thus searched for a second minimum in the excited state potential energy surface (PES) that could explain these intense transitions from $635 \mathrm{~cm}^{-1}$. CC2 optimization of the $\pi \pi^{*}$ with symmetry restriction (Cs point group as in the ground electronic state) has converged to a minimum located only $210 \mathrm{~cm}^{-1}$ above the adiabatic minimum. Its simulated Franck Condon spectrum is reported in figure 7 , with its origin set at the $635 \mathrm{~cm}^{-1}$ band of the experimental spectrum. In this Cs structure, only the in-plane vibration modes and even quanta of out-of-plane vibrations are symmetry allowed. The simulated spectrum of the planar structure matches most of the intense experimental transitions, both in position and in intensity. The first calculated transition corresponds to 2 quanta of the $v_{1}$ out-of-plane mode $(+62$ $\left.\mathrm{cm}^{-1}\right)$, and all the others are in-plane vibrations at 377, 514, 551, 804, 955 and $996 \mathrm{~cm}^{-1}$. Two intense transitions of the experimental spectrum at $+792 \mathrm{~cm}^{-1}$ and $+1010 \mathrm{~cm}^{-1}$ are not reproduced in the simulated spectrum of the Cs structure. However, these transitions are quite close to the frequencies of the in-plane motion mode $1\left(+795 \mathrm{~cm}^{-1}\right)$ and mode $18 \mathrm{a}\left(+997 \mathrm{~cm}^{-1}\right)$ of the adiabatic minimum 
structure. It thus seems that the vibronic transitions of the adiabatic minimum borrow oscillator strength from the local Cs minimum structure as soon as it becomes energetically accessible. It should be finally noted that at the CC2/aug-cc-pVDZ level of calculation, the $S_{1}$ planar structure has one imaginary frequency of $-312 \mathrm{~cm}^{-1}$ corresponding to the out-of-plane bending mode of the $\mathrm{NH}^{+}$ group. We cannot assess if this minimum is a true transition state that is probed in the excitation spectrum or if the PES is too flat for a proper description at the CC2 level. In overall, the experimental spectrum of $2-\mathrm{APH}^{+}$comprises two distinct minima of the $\pi \pi^{*}$ surface with specific vibronic progressions. These two local minima are close in energy and are related to structures with small deformations having different Franck Condon activity from the planar ground electronic state.

\section{3- $\mathrm{APH}^{+}$}

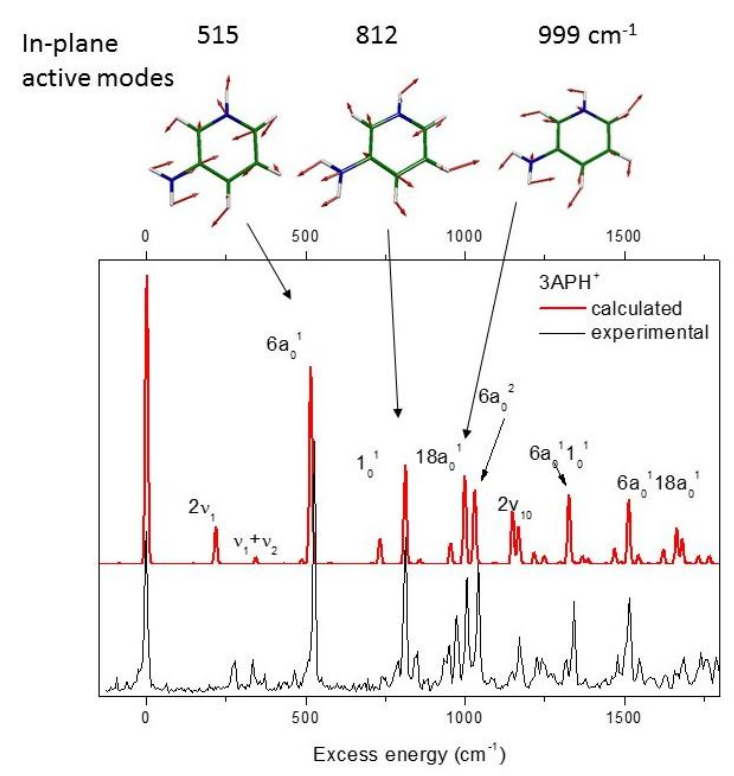

Figure 8: Comparison of the experimental and the Franck-Condon simulated spectrum of 3-APH ${ }^{+}(\mathrm{Cs}$ point group). The origin of the calculated spectrum is set at the experimental band origin.

The absence of low frequency modes in the experimental spectrum of 3-APH ${ }^{+}$suggests that the structure of $3-\mathrm{APH}^{+}$is similar in the ground and excited states, which is confirmed by quantum chemistry calculations. The equilibrium ground and excited state geometries are indeed planar without ring puckering. This is in contrast with $2-\mathrm{APH}^{+}$, and all the geometry optimizations have converged to the same structure even when started from non-planar structures $\left(\mathrm{NH}_{2}\right.$ twist and ring deformation). The first two excited states have $\pi \pi^{*}$ character, and their adiabatic transition energies (corrected for $\triangle \mathrm{ZPE}$ ) are calculated at $3.60 \mathrm{eV}$ and $4.82 \mathrm{eV}$, i.e. within $\pm 0.05 \mathrm{eV}$ of the experimental values (See Figure SI3 for the overall photo-fragmentation spectrum from $225 \mathrm{~nm}$ to $340 \mathrm{~nm}$ ). In the planar structure (Cs point group), only totally symmetric vibrational modes are allowed, i. e. the in- 
plane vibration and even quanta of the out-of-plane motion. The in-plane modes 6a, 1 and 18a are calculated at 515, 812 and $999 \mathrm{~cm}^{-1}$ that are in perfect agreement with the experimental values of 527,813 and $1007 \mathrm{~cm}^{-1}$. The simulated Franck-Condon spectrum of 3-APH ${ }^{+}$is plotted in Figure 8 and nicely reproduces the experimental data, which supports the assignment of the intense vibronic transitions.

\section{Deactivation mechanism following UV excitation}

One of the striking results is the absence of fragmentation for 3- $\mathrm{APH}^{+}$and $4-\mathrm{APH}^{+}$at the band origin while 2-APH ${ }^{+}$undergoes dissociation following UV excitation. In the two former molecules, photo fragmentation opens following UV excitation with some excess energy in the excited state. It requires about $1500 \mathrm{~cm}^{-1}$ in $3-\mathrm{APH}^{+}$and only $500 \mathrm{~cm}^{-1}$ in $4-\mathrm{APH}^{+}$. In all cases, the fragmentation channels observed through one-color excitation are those obtained in CID experiment. Besides, the UV-only fragmentation kinetics recorded for the three aminopyridine is quite long, from $450 \mu \mathrm{s}$ to few ms, incompatible with direct dissociation from the excited state. All these results strongly suggest that, when these protonated aminopyridine fragment after UV excitation, IC is the deactivation mechanism.

\section{Fragmentation channels following IC: $\mathrm{NH}_{3}$ and $\mathrm{HCN}$ loses}

For $2-\mathrm{APH}^{+}, \mathrm{m} / \mathrm{z} 78$ ionic fragment $\left(\mathrm{NH}_{3}\right.$ loss) is detected with a fragmentation kinetics of $450 \mu \mathrm{s}$, consistent with dissociation in the ground state. We have located the transition state for the proton transfer reaction to the amino group at $1.8 \mathrm{eV}$, and the dissociation limit is found at $3.8 \mathrm{eV}$ (B3LYP/6$\left.31+G^{*}\right)$. It should be stressed that excited state proton transfer (ESPT) reaction to the amino group is not energetically possible. The adiabatic excited state energy of 2-AP protonated on the amino group is $1.6 \mathrm{eV}$ higher than the $\mathrm{S}_{1}$ state of the $\mathrm{NH}^{+}$form. For $3-\mathrm{APH}^{+}$, a unique channel is detected at $\mathrm{m} / \mathrm{z} 68$ associated with the loss of $\mathrm{HCN}$ with a fragmentation kinetics of $2 \mathrm{~ms}$. In 4-APH ${ }^{+}, \mathrm{m} / \mathrm{z} 68$ (HCN loss) and $\mathrm{m} / \mathrm{z} 78$ ( $\mathrm{NH}_{3}$ loss) fragments are produced. These two fragmentation channels have the same slow kinetics, in the order of $3 \mathrm{~ms}$, so they are issued from statistical fragmentation in the ground electronic state. Such HCN neutral loss is usually observed through CID experiments on protonated diazines and DNA bases. For instance, Wang et al. ${ }^{25}$ have calculated (B3LYP/6-311++G(d,p)) the HCN loss reaction in the ground state of protonated diazines. In 1,3-diazines, proton transfer to the adjacent carbon atom is the limiting step with a transition state (TS) energy of $3.25 \mathrm{eV}$. In $3-\mathrm{APH}^{+}$, we have estimated (B3LYP/6-31+G* level) the energetics ( $E_{Z P E}$ Enthalpy corrected by the ZPE) of the HCN loss at $2.8 \mathrm{eV}$ with a TS for the proton transfer in $\mathrm{C}_{2}$ position at $2.67 \mathrm{eV}$. $\mathrm{HCN}$ loss from this $\mathrm{C}_{2} \mathrm{H}^{+}$ isomer is thus almost spontaneous with very low activation energy. 
Table 3: Calculated adiabatic $\mathrm{S}_{1}$ energies of 2- 3- and 4- $\mathrm{APH}^{+}$protonated on the nitrogen $\left(\mathrm{NH}^{+}\right)$or carbon $\left(\mathrm{C}_{2}\right.$ or $\mathrm{C}_{6}$ ) atoms. All excited state energies (CC2/aug-cc-pVDZ) compared to the ground state $\mathrm{NH}^{+}$energies are not corrected by the $\Delta_{\mathrm{ZPE}}$ between the ground and excited states. $\Delta \mathrm{E}$ ESPT gives the energetic of the excited state proton transfer reaction. All values in eV.

\begin{tabular}{cccccccc}
\hline & \multicolumn{2}{c}{ 2-APH } & \multicolumn{3}{c}{ 3- $\mathbf{A P H}^{+}$} & \multicolumn{3}{c}{ 4-APH } \\
& $\mathrm{NH}^{+}$ & $\mathrm{C}_{6} \mathrm{H}^{+}$ & $\mathrm{NH}^{+}$ & $\mathrm{C}_{2} \mathrm{H}^{+}$ & $\mathrm{C}_{6} \mathrm{H}^{+}$ & $\mathrm{NH}^{+}$ & $\mathrm{C}_{2} \mathrm{H}^{+}$ \\
\cline { 2 - 8 } $\mathrm{S}_{1}$ & 4.16 & $3.61^{\mathrm{a}}$ & 3.75 & 3.95 & 4.20 & 4.76 & $4.34^{\mathrm{a}}$ \\
$\Delta \mathrm{E}$ ESPT & & -0.55 & & +0.20 & +0.45 & & -0.42 \\
\hline a leads to IC & & & & & & &
\end{tabular}

Proton transfer reaction from the pyridinic nitrogen to the adjacent carbon atom is invoked in the fragmentation mechanism leading to the HCN loss in the ground state. ${ }^{25}$ We have investigated the excited state proton transfer (ESPT) reaction from the nitrogen $\left(\mathrm{NH}^{+}\right)$to the adjacent carbon $\left(\mathrm{C}_{2}\right.$ or $\mathrm{C}_{6}$ ) atoms through $\mathrm{CC} 2$ calculations for the three aminopyridine. The adiabatic energies of the $\mathrm{S}_{1}$ state of the three aminopyridine are reported in Table 3. While protonation on the carbon atom is highly endothermic in the ground state by more than $2 \mathrm{eV}$ for all molecules, it becomes competitive in the excited state. ESPT to $\mathrm{C}_{2}$ is slightly endothermic in $3-\mathrm{APH}^{+}$by $0.2 \mathrm{eV}$, which is within the error expected for this calculation. It is thus difficult to firmly assert whether or not ESPT can occur in 3$\mathrm{APH}^{+}$. In $2-\mathrm{APH}^{+}$and $4-\mathrm{APH}^{+}, \mathrm{ESPT}$ is energetically open with an exothermicity $\triangle \mathrm{E}$ in the order of $0.4 / 0.5 \mathrm{eV}$. Note that in the protonated carbon structures, there is no minimum of the PES since the geometry optimizations of the $S_{1}$ state have led to a conical intersection with the ground state. The well resolved vibrational electronic spectroscopy along with the long excited state lifetimes in these systems imply that, if ESPT occurs, it should go through tunneling. Localization of the transition state for the proton transfer reaction requires multi reference excited state calculations which are out of the scope of this study. However, it is thought that ESPT from the pyridinic nitrogen to the adjacent carbon atom triggers efficient $\mathrm{IC}$ leading to dissociation in the ground state.

\section{Radiative vs excited state lifetimes}

The measured $\mathrm{S}_{1}$ lifetime of $3-\mathrm{APH}^{+}$is $25 \pm 5 \mathrm{~ns}$, which is comparable to the radiative lifetime calculated at $22.4 \mathrm{~ns}^{26}$ Besides, the absence of fragmentation around the band origin implies that the system does not undergo IC until $1500 \mathrm{~cm}^{-1}$ of excess energy in the $S_{1}$ state. This suggest that the only deactivation mechanism in $3-\mathrm{APH}^{+}$is fluorescence from the origin up to roughly $1500 \mathrm{~cm}^{-1}$ of excess energy. It is noteworthy that the excited state lifetime of neutral 3-AP is much shorter, about $0.4 \mathrm{~ns}$ at the origin. ${ }^{27}$ In $2-\mathrm{APH}^{+}$, the excited state lifetime decreases as the excess energy increases from less than $8 \mathrm{~ns}$ (within the experimental time resolution limited by the cross correlation of the 
nanosecond lasers) at the band origin to $1 \mathrm{~ns}$ at $+2000 \mathrm{~cm}^{-1}$ (see Figure 5). The radiative lifetime is estimated at $9.4 \mathrm{~ns},{ }^{26}$ slightly longer than the excited state lifetime but within the uncertainty of such estimation. Neutral 2-AP has an excited state lifetime of $1.89 \mathrm{~ns} .{ }^{28}$ Here again, there is a lengthening of the excited state lifetime upon protonation. 2- $\mathrm{APH}^{+}$fragments after IC even at the band origin, but we can anticipate that the fluorescence yield should be high. Note that for these two aminopyridine molecules, fluorescence study of the neutral and cationic forms in liquid has evidenced the large increase of the fluorescence quantum yield upon protonation. ${ }^{10}$ The low fluorescence quantum yield in neutral aminopyridine (less than 0.1 ) has been rationalized by the coupling of the $\pi \pi^{*}$ state with the low lying $n_{N} \pi^{*}$ state, with the lone pair orbital of the pyridinic nitrogen. Since this $n_{N} \pi^{*}$ charge transfer state is absent in the protonated species, the $\pi \pi^{*}$ excited state lifetime gets longer.

The situation is quite different in 4- $\mathrm{APH}^{+}$. The excited state lifetime of 4- $\mathrm{APH}^{+}$is significantly shorter than the two other protonated aminopyridine, $700 \mathrm{ps}$ at the origin. It is noteworthy that the calculated radiative lifetime is longer, around 3 ns. Besides, a long decay time of $2 \mu$ s has been measured with ns lasers, which reveals the involvement of a long lived excited state in the photo dynamics of 4- $\mathrm{APH}^{+}$. So, the absence of fragmentation at the band origin and the fact that the excited state lifetime is not limited by the radiative lifetime strongly suggests that a process leading to a long-lived $(2 \mu \mathrm{s})$ excited state occurs in this molecule. The $2 \mu \mathrm{s}$ lifetime raises the question of inter system crossing (ISC) in this molecule. As it is discussed below, a twisted intramolecular charge transfer mechanism is more likely to occur.

\section{Twisted Intramolecular Charge Transfer (TICT) in 4-APH}

In the ground state, 4- $\mathrm{APH}^{+}$is planar and belongs to the $\mathrm{C}_{2 v}$ point group. Contrary to the other amino pyridines, 4- $\mathrm{APH}^{+}$has a quite different excited state manifold at the $\mathrm{C}_{2 \mathrm{v}}$ ground state structure. The two first excited states $S_{1}$ and $S_{2}$ are quasi degenerated, their vertical transition energy being calculated at 5.11 and $5.13 \mathrm{eV}$. They both correspond to $\pi-\pi^{*}$ transitions with a different LUMO unoccupied frontier molecular orbital (Table 1 ). When keeping the $C_{2 v}$ symmetry, geometry optimizations of the $S_{1}$ and $S_{2}$ states lead to adiabatic energies of $4.78 \mathrm{eV}$ (for $A_{1}$ ) and $4.71 \mathrm{eV}$ (for $B_{1}$ ). However, these optimized structures are not true minima since 4 or 5 negative frequencies have been calculated for each excited state.

Geometry optimization has also been performed while keeping the $\mathrm{NH}_{2}$ group in the plane of the aromatic ring (fixed dihedral angle $\mathrm{CCNH}$ at $0^{\circ}$ ), which should correspond to the active Franck Condon region. In this structure, there is a pyramidalization at the carbon atom in position 2 with a $\mathrm{C}_{4} \mathrm{C}_{3} \mathrm{C}_{2} \mathrm{~N}$ dihedral angle of $19^{\circ}$ (Figure 6). In that case, a true minimum without imaginary frequency 
has been found, with an adiabatic transition energy (corrected by the $\Delta_{\mathrm{ZPE}}$ ) of $4.58 \mathrm{eV}$, ca. only 0.03 $\mathrm{eV}$ to the red of the experimental band origin (see Table 2). This calculated $\pi \pi^{*}$ transition indeed corresponds to the experimental band origin. The first active out-of-plane modes are calculated at 86 $\mathrm{cm}^{-1}, 208 \mathrm{~cm}^{-1}$ and $356 \mathrm{~cm}^{-1}$, quite close to the experimental transitions. So the few intense vibronic transitions observed in the 2-color excitation scheme are assigned to this $\pi \pi^{*}$ state with $\mathrm{NH}_{2}$ in the plane of the pyridine ring.

Geometry optimization of the $\pi \pi^{*}$ state without symmetry constraints has led to a totally different structure. The symmetry in the optimized $S_{1}$ structure is reduced to $C s$ point group, with the amino group twisted by $90^{\circ}$ and bent out of the plane of the aromatic ring by $18^{\circ}$ (Figure 6). This structure is a true minimum of the potential energy surface with no imaginary frequency. The frontier molecular orbitals of the $S_{1}$ state in planar and twisted structures are plotted in Figure 9. It should be stressed that the mirror plane of the Cs structure comprises the $\mathrm{NH}_{2}$ moiety and is perpendicular to the plane of the aromatic ring. In this twisted structure, the first excited state has a charge transfer character of $A^{\prime \prime}$ symmetry, characterized by a transition from the $\mathrm{n}_{\mathrm{NH} 2}$ lone pair and $\pi_{\text {arom }}$ orbitals (9a") to the anti-bonding orbital of the aromatic ring (17a'). This anti-bonding orbital of the pyridine ring (17a') is totally symmetric in this Cs structure, and is thus considered as a $\sigma_{\text {arom }}{ }^{*}$ orbital. Strictly speaking, this defines a $\pi-\sigma_{\text {arom }}{ }^{*}$ transition ( $A^{\prime \prime}$ ), which however closely resembles to the usual $\pi-\pi^{*}$ transition ( $\mathrm{A}^{\prime}$ symmetry) when the mirror plan coincides with the aromatic ring (inplane $\mathrm{NH}_{2}$ ). The adiabatic transition energy of the twisted structure is calculated at $4.20 \mathrm{eV}$ (Table 2), underestimated by $0.41 \mathrm{eV}$ as compared to the experimental band origin. This is about ten times larger than the uncertainty found for the other systems with the CC2 method. Due to the absence of Franck Condon activity in this Cs structure, this twisted adiabatic minimum cannot not be directly reached through UV excitation and is considered as a dark state and responsible for the non-radiative decay. After UV excitation in the active Franck Condon region (in-plane $\mathrm{NH}_{2}$ ), the locally excited $\pi \pi^{*}$ state $\left(A^{\prime}\right)$ evolves into the $C T$ state $\left(A^{\prime \prime}\right)$ in the course of the twist motion.

This charge transfer state $\left(A^{\prime \prime}\right)$ is quite similar to the twisted intramolecular charge transfer state (TICT) invoked in similar systems such as 4-( $\mathrm{N}, \mathrm{N}$-dimethylamino)-benzonitrile DMABN and DMABME in solvent. ${ }^{11} \mathrm{It}$ is noteworthy that TICT process is observed in solution where the solvent plays a crucial role in stabilizing electronic states with large dipole moment such as in CT state. ${ }^{29}$ In the gas phase, it has been shown that at least two water molecules are required to trigger the TICT process in DMABME. ${ }^{30}$ Excited state dynamics studies have been conducted both in liquid and solvated clusters in the gas phase. Ultrafast TICT formation in small DMAME- $\left(\mathrm{CH}_{3} \mathrm{CN}\right)_{n}$ clusters has been measured in the 1 to 5 ps time scale, dynamics that gets faster as the cluster size increases. ${ }^{31}$ 
DMABN exhibits also fast intramolecular CT process in the order of 10-30 ps depending on the solvent. ${ }^{32}$ In bare DMABN molecule, ultrafast relaxation dynamics of the $S_{2}$ charge transfer state $\left(L_{a}-\right.$ like) from the Franck-Condon geometry (planar $\mathrm{NH}_{2}$ ) towards the TICT state $\left(90^{\circ}\right)$ has been measured in the sub picosecond regime. ${ }^{33,34}$ In these experiments, the femtosecond pump laser ( $266 \mathrm{~nm}$ or 270 $\mathrm{nm}$ ) brings a large excess energy, about $0.6 \mathrm{eV}$ above the band origin of the $S_{1}$ ( $L_{b}$-like) state, which should drastically shorten the dynamics.
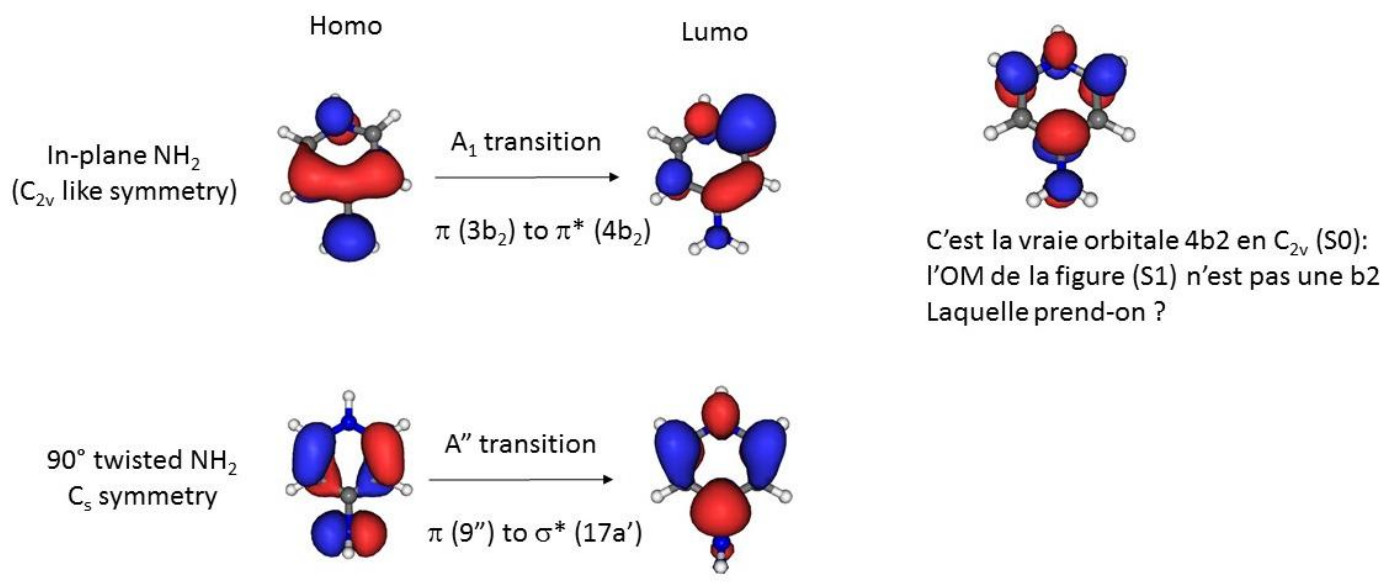

L'OM de la figure $(\mathrm{S} 1)$

Figure 9: Frontier Molecular Orbitals (MOs) of the locally excited $\pi \pi^{*}$ state (in-plane $\mathrm{NH}_{2}$ ) and charge transfer $(\mathrm{CT}) \pi \sigma_{\text {arom }}{ }^{*}$ state of $4-\mathrm{APH}^{+}$.

The excited state lifetime recorded in the case of $4-\mathrm{APH}^{+}$points out to the relatively slow dynamics towards the TICT state at the band origin, in the order of $700 \mathrm{ps}$. The dynamics becomes faster as the excess energy in the locally excited state increases and drops down to few tens of ps $1000 \mathrm{~cm}^{-1}$ above the origin. Although the adiabatic CT state lies $0.4 \mathrm{eV}$ below the adiabatic $\pi \pi^{*}$ state, the PES in the FC region is rather flat, as revealed by the relatively small energy gradient calculated during the first steps of the $\mathrm{S}_{1}$ optimization. However, as soon as the $\mathrm{NH}_{2}$ group starts to twist, the $\pi \pi^{*}$ state develops quickly towards the CT state without barrier. The oscillator strength for radiative emission from the CT state is quite low, in the order of $310^{-4}$ (in length gauge unit), leading to a radiative lifetime of about $10 \mu \mathrm{s}$ (the $0_{0}{ }^{0}$ emission wavelength being calculated at $410 \mathrm{~nm}$ ). This puts a higher limit for the experimental lifetime of the CT state, knowing that $0.4 \mathrm{eV}$ of excess energy is gained during the TICT process. It should also be stressed that in the TICT structure, we have not found a path for internal conversion to the ground state that would lead to dissociation. The absence of fragmentation around the band origin is thus consistent with the formation of the TICT state. Finally, we have calculated the oscillator strengths from the TICT state to the manifold of upper 
excited states up to $4 \mathrm{eV}$ higher, in order to compare with the absorption of the $355 \mathrm{~nm}$ probe laser $(3.5 \mathrm{eV})$ that leads to the specific $\mathrm{m} / \mathrm{z} 79$ ionic fragment $\left(\mathrm{NH}_{2}\right.$ loss). Interestingly, the $\mathrm{A}^{\prime}$ transition towards the dissociative $\sigma_{\mathrm{NH} 2}{ }^{*}$ orbital $\left(\mathrm{S}_{5}\right.$ state) has the largest oscillator strength (0.024 in length gauge unit) by more than 2 order of magnitude over the other ones and is calculated at $3.25 \mathrm{eV}$, ca. in the range of the probe photon energy. So the $2 \mu \mathrm{s}$ decay recorded in the pump/probe experiment of 4- $\mathrm{APH}^{+}$when detecting the specific $\mathrm{NH}_{2}$ loss fragment is compatible with the excited state lifetime of the TICT state.

Table 4: singlet and triplet excited state manifold at the optimized geometry of the $\mathrm{S}_{1}$ state (in-plane $\mathrm{NH}_{2}$ ) and (twisted $\mathrm{NH}_{2}$ ). All values (in eV) compared to the ground state optimized $\mathrm{C}_{2 \mathrm{v}}$ structure.

\begin{tabular}{cccc}
\hline 4-APH ${ }^{+}$(in-plane $\left.\mathrm{NH}_{2}\right)$ & \multicolumn{3}{c}{ 4-APH $\left(\right.$ twisted $\left.\mathrm{NH}_{2} \mathrm{C}_{\mathrm{s}}\right)$} \\
\hline Elec. Conf. & $\mathrm{eV}$ & Elec. Conf. & $\mathrm{eV}$ \\
\hline $\mathrm{T}_{1}\left(\mathrm{~A}_{1}\right)\left(3 \mathrm{~b}_{2}-4 \mathrm{~b}_{2}\right)$ & 4.10 & $\mathrm{~T}_{1}\left(\mathrm{~A}^{\prime \prime}\right)\left(9 \mathrm{a}^{\prime \prime}-17 \mathrm{a}^{\prime}\right)$ & 4.32 \\
$\mathrm{~T}_{2}\left(\mathrm{~B}_{1}\right)\left(1 \mathrm{a}_{2}-4 \mathrm{~b}_{2}\right)$ & 4.73 & $\mathrm{~S}_{1}\left(\mathrm{~A}^{\prime \prime}\right)\left(9 \mathrm{a}^{\prime \prime}-17 \mathrm{a}^{\prime}\right)$ & 4.35 \\
$\mathrm{~S}_{1}\left(\mathrm{~A}_{1}\right)\left(3 \mathrm{~b}_{2}-4 \mathrm{~b}_{2}\right)$ & 4.76 & $\mathrm{~T}_{2}\left(\mathrm{~A}^{\prime}\right)\left(16 \mathrm{a}^{\prime}-17 \mathrm{a}^{\prime}\right)$ & 5.43 \\
$\mathrm{~T}_{3}\left(\mathrm{~B}_{1}\right)\left(3 \mathrm{~b}_{2}-2 \mathrm{a}_{2}\right)$ & 4.99 & $\mathrm{~T}_{3}\left(\mathrm{~A}^{\prime \prime}\right)\left(8 \mathrm{a}^{\prime \prime}-17 \mathrm{a}^{\prime}\right)$ & 5.63 \\
$\mathrm{~S}_{2}\left(\mathrm{~B}_{1}\right)\left(3 \mathrm{~b}_{2}-2 \mathrm{a}_{2}\right)$ & 5.13 & $\mathrm{~T}_{4}\left(\mathrm{~A}^{\prime}\right)\left(9 \mathrm{a}^{\prime \prime}-10 \mathrm{a}^{\prime \prime}\right)$ & 5.99 \\
$\mathrm{~T}_{4}\left(\mathrm{~B}_{1}\right)\left(3 \mathrm{~b}_{2}-4 \mathrm{~b}_{2}\right)$ & 5.33 & $\mathrm{~S}_{2}\left(\mathrm{~A}^{\prime}\right)\left(9 \mathrm{a}^{\prime \prime}-10 \mathrm{a}^{\prime \prime}\right)$ & 6.15 \\
$\mathrm{~T}_{5}\left(\mathrm{~B}_{1}\right)\left(1 \mathrm{a}_{2}-4 \mathrm{~b}_{2}\right)$ & 6.30 & $\mathrm{~S}_{3}\left(\mathrm{~A}^{\prime \prime}\right)\left(8 \mathrm{a}^{\prime \prime}-17 \mathrm{a}^{\prime}\right)$ & 6.31 \\
\hline
\end{tabular}

\$: MO representation of the $C_{2 v}$ structure that correlates with those without symmetry.

It is worth mentioning that ISC could, in principle, be invoked to rationalize the shortening of the $\pi \pi^{*}$ state lifetime compared to the radiative one and the long $2 \mu$ s decay in 4-APH ${ }^{+}$In first approximation and without strong vibronic coupling, ${ }^{35,36}$ ISC is forbidden between electronic state of same symmetry, for instance ${ }^{1} \pi \pi^{*}$ to ${ }^{3} \pi \pi^{*}$. For 2 - and $3-\mathrm{APH}^{+}$, only $\mathrm{A}^{\prime}$ symmetry states are in the manifold of the locally excited state which precludes ISC, in agreement with the experimental results. In contrast, for $4-\mathrm{APH}^{+}$, singlet and triplet states of different symmetries $\left(\mathrm{A}_{1}\right.$ and $\left.\mathrm{B}_{1}\right)$ are within the manifold of the low-lying excited states (SI Table SI 1). At the optimized geometry of the in-plane $\mathrm{NH}_{2}$ structures (Franck-Condon active region), the first and second triplet states lie below the singlet $\pi \pi^{*}$ state by $0.66 \mathrm{eV}$ and $0.03 \mathrm{eV}$, respectively (Table 4). The ${ }^{1} \pi \pi^{*}$ state optimized structure is close to the $\mathrm{C}_{2 \mathrm{v}}$ symmetry and despite the absence of symmetry, one can make connection with the excited states manifold of the $C_{2 v}$ structure. A careful inspection of the molecular orbitals allows to connect the $S_{1} \pi \pi^{*}$ state to the $A_{1}$ symmetry and the triplet $T_{1}$ and $T_{2}$ states to $A_{1}$ and $B_{1}$ symmetries, respectively. According to the energy gap law, ${ }^{37,38}$ the almost degenerated $S_{1}\left(A_{1}\right)$ and $T_{2}\left(B_{1}\right)$ states might have a sizeable ISC probability. It should also be stressed that, in the twisted optimized 
structure (Table 4), the first singlet and triplet CT states $\left(A^{\prime \prime}\right)$ are degenerated (within $0.03 \mathrm{eV}$ ) due to the uncoupled electron in the $\pi$ and lone pair orbitals. So in the course of the TICT process, ISC is symmetry allowed. However, the $T_{1}$ optimized structure $\left({ }^{3} \pi \pi^{*}, A_{1}\right.$ symmetry) is planar, in a $C_{2 v}$ symmetry as in the ground state. This is in agreement with the results of Serrano-Andres et al. ${ }^{39}$ in the case of aminobenzonitrile (ABN) and DMABN. This ${ }^{3} \pi \pi^{*}$ optimized structure lies $0.5 \mathrm{eV}$ below the ${ }^{3} \mathrm{CT}$ state, so if ISC occurs in the course of the TICT formation, the system should undergo a reverse twist motion of the amino group leading to the adiabatic $T_{1}$ planar structure. In this planar geometry, the only transition that has a large oscillator strength ( 0.13 length gauge unit) corresponds to a $\pi$ $\left(2 b_{2}\right)$ to $\pi^{*}\left(4 b_{2}\right)$ transition $\left(A_{1}\right)$ calculated at $3.12 \mathrm{eV}$ which does not lead to $\mathrm{NH}_{2}$ loss. Therefore, although ISC can in principle occur in 4- $\mathrm{APH}^{+}$, there is no experimental evidence for this process and in any case, it does not need to be invoked to explain the $2 \mu$ s long decay signal recorded on the $\mathrm{NH}_{2}$ loss fragment with the 2-color excitation scheme.

\section{Conclusions}

We have investigated the photo fragmentation processes in protonated aminopyridine through a combined experimental and theoretical study. Although being rather simple aromatic molecules, their photo dynamics are much more complex than expected. One of the striking results of this study is the drastic change in the fragmentation branching ratio in 4- $\mathrm{APH}^{+}$. Within the first $500 \mathrm{~cm}^{-1}$ above the origin, TICT process is the only non-radiative decay channel, evidenced by the detection of the $\mathrm{NH}_{2}$ loss channel in the 2-color excitation scheme. Above this excess energy, internal conversion to the ground state opens and becomes the only deactivation path with $1000 \mathrm{~cm}^{-1}$ of excess energy. The

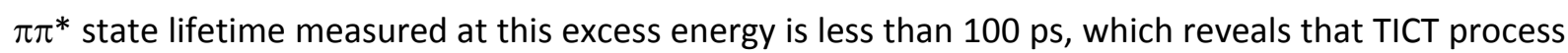
is not a very fast process even with such excess energy. The path to IC in the protonated aminopyridine molecules that we have evidenced in this study is excited state proton transfer from the protonated pyridinic nitrogen towards the adjacent carbon atom. This reaction is exothermic in 4- $\mathrm{APH}^{+}$by more than $0.5 \mathrm{eV}$, an energy even lower than the optimized TICT state. This proton transfer reaction must however go through an energy barrier, which might explain the well resolved electronic spectroscopy recorded below the onset of the reaction. The CC2 calculations performed in this study seem to give a quite reliable picture of the excited state properties. This simple and relatively small system should provide a benchmark system for nonadiabatic excited state dynamics simulation.

\section{Acknowledgments}


This work has been supported by the ANR Research Grant (ANR2010BLANC040501) and CNRS GDR EMIE. We acknowledge the use of the computing facility clusters GMPCS of the LUMAT federation (FRLUMAT 2764) and MAGI of the University Paris 13.

\section{References}

(1) Kleinermanns, K.; Nachtigallová, D.; de Vries, M. S. Excited State Dynamics of DNA Bases. Int. Rev. Phys. Chem. 2013, 32 (2), 308-342.

(2) Crespo-Hernández, C. E.; Cohen, B.; Hare, P. M.; Kohler, B. Ultrafast Excited-State Dynamics in Nucleic Acids. Chem. Rev. 2004, 104 (4), 1977-2020.

(3) Merchán, M.; Serrano-Andrés, L. Ultrafast Internal Conversion of Excited Cytosine via the Lowest Pipi Electronic Singlet State. J. Am. Chem. Soc. 2003, 125 (27), 8108-8109.

(4) Zgierski, M. Z.; Patchkovskii, S.; Lim, E. C. Ab Initio Study of a Biradical Radiationless Decay Channel of the Lowest Excited Electronic State of Cytosine and Its Derivatives. J. Chem. Phys. 2005, $123(8), 081101$.

(5) Barbatti, M.; Szymczak, J. J.; Aquino, A. J. A.; Nachtigallová, D.; Lischka, H. The Decay Mechanism of Photoexcited Guanine - A Nonadiabatic Dynamics Study. J. Chem. Phys. 2011, 134 (1), 014304.

(6) González, L.; Escudero, D.; Serrano-Andrés, L. Progress and Challenges in the Calculation of Electronic Excited States. Chemphyschem 2012, 13 (1), 28-51.

(7) Pino, G. A.; Feraud, G.; Broquier, M.; Gregoire, G.; Soorkia, S.; Dedonder, C.; Jouvet. Non Radiative Processes in Protonated Aromatic Azine, Diazines and Pyrimidine Bases. Phys. Chem. Chem. Phys. 2015, in press.

(8) Berdakin, M.; Féraud, G.; Dedonder-Lardeux, C.; Jouvet, C.; Pino, G. A. Excited States of Protonated DNA/RNA Bases. Phys. Chem. Chem. Phys. 2014, 16 (22), 10643.

(9) Zhang, F.; Ai, Y.-J.; Luo, Y.; Fang, W.-H. Nonradiative Decay of the Lowest Excited Singlet State of 2-Aminopyridine Is Considerably Faster than the Radiative Decay. J. Chem. Phys. 2009, 130 (14), 144315.

(10) Weisstuch, A.; Testa, A. C. Fluorescence Study of Aminopyridines. J. Phys. Chem. 1968, 72 (6), 1982-1987.

(11) Grabowski, Z. R.; Rotkiewicz, K.; Rettig, W. Structural Changes Accompanying Intramolecular Electron Transfer: Focus on Twisted Intramolecular Charge-Transfer States and Structures. Chem. Rev. 2003, 103 (10), 3899-4032.

(12) Weber, W.; Helms, V.; McCammon, J. A.; Langhoff, P. W. Shedding Light on the Dark and Weakly Fluorescent States of Green Fluorescent Proteins. Proc. Natl. Acad. Sci. 1999, 96 (11), 6177-6182.

(13) Adamson, B. D.; Coughlan, N. J. A.; Continetti, R. E.; Bieske, E. J. Changing the Shape of 
Molecular lons: Photoisomerization Action Spectroscopy in the Gas Phase. Phys. Chem. Chem. Phys. 2013, 15 (24), 9540.

(14) Broquier, M.; Soorkia, S.; Grégoire, G. A Comprehensive Study of Cold Protonated Tyramine: UV Photodissociation Experiments and Ab Initio Calculations. Phys. Chem. Chem. Phys. 2015, 17 (39), 25854-25862.

(15) Ahlrichs, R.; Bär, M.; Häser, M.; Horn, H.; Kölmel, C. Electronic Structure Calculations on Workstation Computers: The Program System Turbomole. Chem. Phys. Lett. 1989, 162 (3), 165-169.

(16) Weigend, F.; Häser, M. RI-MP2: First Derivatives and Global Consistency. Theor. Chem. Accounts Theory, Comput. Model. (Theoretica Chim. Acta) 1997, 97 (1-4), 331-340.

(17) Köhn, A.; Hättig, C. Analytic Gradients for Excited States in the Coupled-Cluster Model CC2 Employing the Resolution-of-the-Identity Approximation. J. Chem. Phys. 2003, 119 (10), 5021.

(18) Hättig, C. Optimization of Auxiliary Basis Sets for RI-MP2 and RI-CC2 Calculations: Core?valence and Quintuple-? Basis Sets for H to Ar and QZVPP Basis Sets for Li to Kr. Phys. Chem. Chem. Phys. 2005, 7 (1), 59.

(19) C. M. Western. PGOPHER, a Program for Simulating Rotational, Vibrational and Electronic Structure. University of Bristol.

(20) NIST, available at http://webbook.nist.gov/chemistry/.

(21) Hop, C. E. C. A.; Dakubu, M.; Holmes, J. L. Do the Aminopyridine Molecular lons Display Aniline- or Pyridine-Type Behaviour? Org. Mass Spectrom. 1988, 23 (8), 609-612.

(22) Lin, J. L.; Wu, R. H.; Tzeng, W. B. Mass Analyzed Threshold Ionization Spectroscopy of 2Aminopyridine Cation. Chem. Phys. Lett. 2002, 353 (1-2), 55-62.

(23) Lin, J. L.; Wu, R. H.; Tzeng, W. B. Mass Analyzed Threshold Ionization Spectroscopy of 3Aminopyridine Cation and Vicinal Substitution Effect. Chem. Phys. 2002, 280 (1-2), 191-203.

(24) He, Y.; Wu, C.; Kong, W. Resonantly Enhanced Two Photon lonization and Zero Kinetic Energy Spectroscopy of Jet-Cooled 4-Aminopyridine. J. Chem. Phys. 2004, 120 (16), 7497.

(25) Wang, Z.-C.; Cole, C. A.; Snow, T. P.; Bierbaum, V. M. Experimetal and Computational Studies of the Formation Mechanism of Protonated Interstellar Diazines. Astrophys. J. 2015, 798 (2), 102.

(26) Bolton, J. R.; Archer, M. D. Calculation of Natural Radiative Lifetimes from the Absorption and Fluorescence Properties of Semiconductors and Molecules. J. Phys. Chem. 1991, 95 (22), 8453-8461.

(27) Kim, B.; Schick, C. P.; Weber, P. M. Time-Delayed Two-Color Photoelectron Spectra of Aniline, 2-Aminopyridine, and 3-Aminopyridine: Snapshots of the Nonadiabatic Curve Crossings. J. Chem. Phys. 1995, 103 (16), 6903.

(28) Hager, J. W.; Leach, G. W.; Demmer, D. R.; Wallace, S. C. Structure and Excited-State Dynamics 
of 2-Aminopyridine van Der Waals Molecules and Hydrogen-Bonded Complexes. J. Phys. Chem. 1987, 91 (14), 3750-3758.

(29) Zachariasse, K. A.; Grobys, M.; von der Haar, T.; Hebecker, A.; Il'ichev, Y. V.; Morawski, O.; Rückert, l.; Kühnle, W. Photo-Induced Intramolecular Charge Transfer and Internal Conversion in Molecules with a Small Energy Gap between S1 and S2. Dynamics and Structure. J. Photochem. Photobiol. A Chem. 1997, 105 (2-3), 373-383.

(30) Zakharov, M.; Krauss, O.; Nosenko, Y.; Brutschy, B.; Dreuw, A. Specific Microsolvation Triggers Dissociation-Mediated Anomalous Red-Shifted Fluorescence in the Gas Phase. J. Am. Chem. Soc. 2009, 131 (2), 461-469.

(31) Grégoire, G.; Dimicoli, I.; Mons, M.; Dedonder-Lardeux, C.; Jouvet, C.; Martrenchard, S.; Solgadi, D. Femtosecond Dynamics of "TICT" State Formation in Small Clusters: The Dimethylaminobenzomethyl Ester-Acetonitrile System. J. Phys. Chem. A 1998, 102 (41), 7896-7902.

(32) Zachariasse, K. A.; Grobys, M.; von der Haar, T.; Hebecker, A.; Il'ichev, Y. V.; Jiang, Y.-B.; Morawski, O.; Kühnle, W. Intramolecular Charge Transfer in the Excited State. Kinetics and Configurational Changes. J. Photochem. Photobiol. A Chem. 1996, 102 (1), 59-70.

(33) Trushin, S. A.; Yatsuhashi, T.; Fuß, W.; Schmid, W. E. Coherent Oscillations in the ChargeTransfer System 4-Dimethylamino-Benzonitrile. Chem. Phys. Lett. 2003, 376 (3-4), 282-291.

(34) Fuß, W.; Pushpa, K. K.; Rettig, W.; Schmid, W. E.; Trushin, S. A. Ultrafast Charge Transfer via a Conical Intersection in Dimethylaminobenzonitrile. Photochem. Photobiol. Sci. 2002, 1 (4), 255-262.

(35) Tatchen, J.; Gilka, N.; Marian, C. M. Intersystem Crossing Driven by Vibronic Spin-orbit Coupling: A Case Study on Psoralen. Phys. Chem. Chem. Phys. 2007, 9 (38), 5209.

(36) El-Sayed, M. A. Spin-Orbit Coupling and the Radiationless Processes in Nitrogen Heterocyclics. J. Chem. Phys. 1963, 38 (12), 2834.

(37) Englman, R.; Jortner, J. The Energy Gap Law for Radiationless Transitions in Large Molecules. Mol. Phys. 1970, 18 (2), 145-164.

(38) Bixon, M.; Jortner, J.; Cortes, J.; Heitele, H.; Michel-Beyerle, M. E. Energy Gap Law for Nonradiative and Radiative Charge Transfer in Isolated and in Solvated Supermolecules. J. Phys. Chem. 1994, 98 (30), 7289-7299.

(39) Serrano-Andres, L.; Merchan, M.; Roos, B. O.; Lindh, R. Theoretical Study of the Internal Charge Transfer in Aminobenzonitriles. J. Am. Chem. Soc. 1995, 117 (11), 3189-3204. 